\title{
Dry turning of X2CrNi18-09 using coated carbide tools: modelling and optimization of multiple performance characteristics
}

\author{
Septi BOUCHERIT*, Sofiane BERKANI*, Mohamed AthmaneYALLESE*, Abdelkrim \\ HADDAD**, Salim BELHADI* \\ *Mechanics and Structures Research Laboratory (LMS), Université 8 Mai 1945 Guelma BP 401 Guelma 24000, Algérie, \\ E-mail: boucherit.sebti@univ-guelma.dz \\ **Laboratory of Applied Mechanics of New Materials (LMANM), Université 8 Mai 1945 Guelma, PO Box 401 Guelma \\ 24000, Algeria \\ cross ref http://dx.doi.org/10.5755/j01.mech.25.6.22367
}

\section{Introduction}

The X2CrNi18-09 Austenitic Stainless Steel (ASS) is an alloy having strategic qualities represented essentially by a good resistance to corrosion and formability along with numerous non-magnetic properties. All these characteristics qualify this type of steel for interesting applications in diverse engineering fields (i.e. chemical equipment, food processing, pressure vessels, cryogenic tanks, paper industry, etc.). However, machining this type of material is more difficult than other steels due of its great tensile strength, its important rate of work hardening, its significant ductility along with its little thermal conduction and its significant tendency of the built-up edge (BUE) formation.

Various investigations aiming to optimize the machinability of this type of material have been performed. I. Korkut et. al. [1] studied the influence of the cutting speed on both the wear of the tool and the surface roughness when turning ASSX2CrNi18-09 using cemented carbide cutting tools. A reduction in tool wear was witnessed when the cutting speed is increased to $180 \mathrm{~m} / \mathrm{min}$. Surface roughness Ra represented by its arithmetical mean deviation was found to decrease with the increase of the cutting speed. Therefore, a correlation was performed between the surface roughness, the tool wear and the chips collected at three speeds of cutting represented by $120 \mathrm{~m} / \mathrm{min}, 150 \mathrm{~m} / \mathrm{min}$ and $180 \mathrm{~m} / \mathrm{min}$. Using the L27 rectangular batch Taguchi design process, S. Nayak, et. al. [2] examined the impact of machining parameters on material removal rate, cutting force and surface roughness during dry machining of X2CrNi18-09 austenitic stainless steel. The Grey relational analysis (GRA) was applied to enhance the parameters related to machining during turning operation. A confirmatory test was performed to back up the findings and an $88.78 \%$ improvement was observed. A. Hamdan et. al. [3] applied the Taguchi statistical method with the objective of optimizing the parameters related to large velocity machining of stainless steel employing coated carbide tool. The common rectangular array of L9 $\left(3^{4}\right)$ was employed, and the results were analyzed for the optimization process using both the ratio of signal to noise $S / N$ response analysis and Pareto ANOVA. The feed rate $f$ was identified as more significant than the cutting speed $V c$ and the depth of cut $a p$, while the lubrication mode did not show any statistical significance.

Using the Taguchi method, P. Selvaraj et. al. [4] took on to optimize the parameters related to dry turning of two distinct levels of nitrogen alloyed duplex stainless steel.
The results achieved demonstrated the feed rate as the dominating parameter affecting the surface roughness and the cutting force $F c$, while the cutting speed showed a significant impact on tool wear. Furthermore, it was demonstrated that the lubricating mode can have significant impact on the indicators related to cutting performance. A. Xavior et. al. [5] investigated the impact of coconut oil on both tool wear and surface roughness while turning X2CrNi18-09 with a carbide tool. They observed that the coconut oil showed better performances than the other cutting fluids as it reduces the wear while improving the surface finish. The optimization of the cutting speed and feed rate with the objective of obtaining favorable performance characteristics was moreover recently reported by numerous researchers i.e. S. Kalidass et. al. [6], M. Rao and K. Venkata Subbaiah [7] and A. Kulkarni et al. [8]. An interesting review was performed by S. Chinchanikar et. al. [9] and Kribes et. al. [10] concerning hardened steel machining.

Most of these studies, interested in evaluating the machining performances involving the roughness of surfaces, the life of the tools, the cutting forces and the morphology of the chip when machining hardened steel with diverse harnesses using coated carbide tools, have shown the benefits of combining a low feed rate and depth of cut with great cutting speeds.

Moreover, the experimental investigations show the influence of the depth of cut and the work piece hardness on the components of the cutting force. However, the work piece hardness and the feed rate are found to be statistically significant on the surface roughness. P. Selvaraj et. al. [11] studied the surface roughness while dry turning X2CrNi1809 ASS operated by TiC (Titanium Carbide) and TiCN (Titanium Carbonitride) coated tungsten carbide cutting tools. They concluded that feed rate was the most impacting parameter over the surface roughness along with the cutting speed and the depth of cut.

In their investigations concerning dry turning using coated carbide tools on duplex stainless steel while applying the RSM method (Response Surface Methodology), M. Krolczyk et. al. [12] observed that the feed rate was the principal factor influencing the surface roughness. P. Selvaraj et. al. [13] investigated the level of influence of the parameters related to machining represented by the spindle speed, the depth of cut in the axial direction, the feed rate on the surface roughness while end milling the duplex stainless steel through the application of the RSM by the prediction equation derived. They concluded that the feed rate is the most significant factor influencing the surface roughness, 
followed by the depth of cut in the axial direction and the spindle speed. With the objective of minimizing the surface roughness while dry turning the $\mathrm{X} 2 \mathrm{CrNi18-09}$ stainless steel, S. Waychal et. al. [14] identified the optima of the operation parameters represented by the cutting speed and the depth of cut as the most impacting factors on the surface roughness. Subsequently, the better surface finish was found at lower feed rates and large cutting speeds. K. SenthilKumar et. al. [15] investigated the machining performance indicators represented by the tool wear, surface roughness, cutting zone temperature and force during hard turning of super duplex stainless steel using uncoated carbide tool. Their experimental results showed that the feed rate is the most dominating factor that influences the surface roughness, while the cutting zone temperature and the force act along the ' $x$ ' axis. The tool wear was further demonstrated to be highly influenced by the depth of cut.

In the present study, a model based on RSM is used to derive a relationship linking the three cutting parameters $V c, f$, and $a p$ and the cutting performance characterized by the surface roughness $R a$, the cutting force $F c$, the specific cutting force $K c$ and the cutting power $P c$ while turning the X2CrNi18-09 ASS. The results achieved were analyzed and optimized using the desirability method.

A complementary confirmation test is performed to evaluate the predicted models.

\section{Experimental procedure}

\subsection{Experimental setup}

The experiment was performed using the lathe 'TOS TRENCIN; model SN40C' that develops a spindle power of $6.6 \mathrm{~kW}$ and a maximum spindle speed of 2000 rpm. The insert used for cutting was a SANDVIK "Ti(C, N)/A12O3/TiN" CVD (Chemical Vapor Deposition) multilayer coated carbide referenced as GC2015 (SNMG 12-0408-MF) [16]. The inserts used for cutting were secured on a tool holder designed PSBNR25x25M12. The workpiece adopted is $\mathrm{X} 2 \mathrm{CrNi18-09}$ ASS with chemical composition $(0.02 \% \mathrm{C}, 16.91 \% \mathrm{Cr}, 7.69 \% \mathrm{Ni}, 0.33 \% \mathrm{Si}, 1.44 \% \mathrm{Mn}$, $0.41 \% \mathrm{Mo}, 72.10 \% \mathrm{Fe}$ and $1.1 \%$ other components). Its dimensions are $100 \mathrm{~mm}$ and $350 \mathrm{~mm}$ in diameter and length respectively.

The mechanical and physical properties of the workpiece are summarized in Table 1.

The three different components of forces represented by the cutting force $F c$, the feed force $F a$ and the thrust $F r$ were measured using a piezoelectric dynamometer (Kistler, model 9121) represented in Fig.1. The measurements were monitored continuously, and recorded in a charge amplifier (model 5019) having three channels. A two-dimensional roughness meter (MitutoyoSurftest-201) was employed for the measurement of the surface roughness $R a$, in a direction parallel to the workpiece axis, according to an examination length of $4 \mathrm{~mm}$ with a cut-off of $0.8 \mathrm{~mm}$ and a measured range of $0.05-40 \mu \mathrm{m}$. To achieve more accuracy and eliminate errors, all the roughness measurements were obtained directly on the same machine without dismantling the workpiece.

Tool flank wear was evaluated by a binocular microscope (Visual Gage 250) equipped with Visual Gage 2.2.0 software.
Table 1

Physical and mechanical properties of X2CrNi18-09

\begin{tabular}{|c|c|c|}
\hline Modulus of elasticityat $20^{\circ} \mathrm{C}, E$ & $\mathrm{GPa}$ & 200 \\
\hline Thermal conductivity, $\lambda$ & $\mathrm{W} \cdot \mathrm{m}^{-1} \cdot \mathrm{K}^{-1}$ & 15 \\
\hline Coefficientdilatation at $100^{\circ} \mathrm{C}, \alpha$ & $10^{-6} \mathrm{C}^{-1}$ & 16 \\
\hline Elongation at break & $\%$ & 45 \\
\hline Hardness, Vickers & $\mathrm{HV}$ & $160-200$ \\
\hline
\end{tabular}

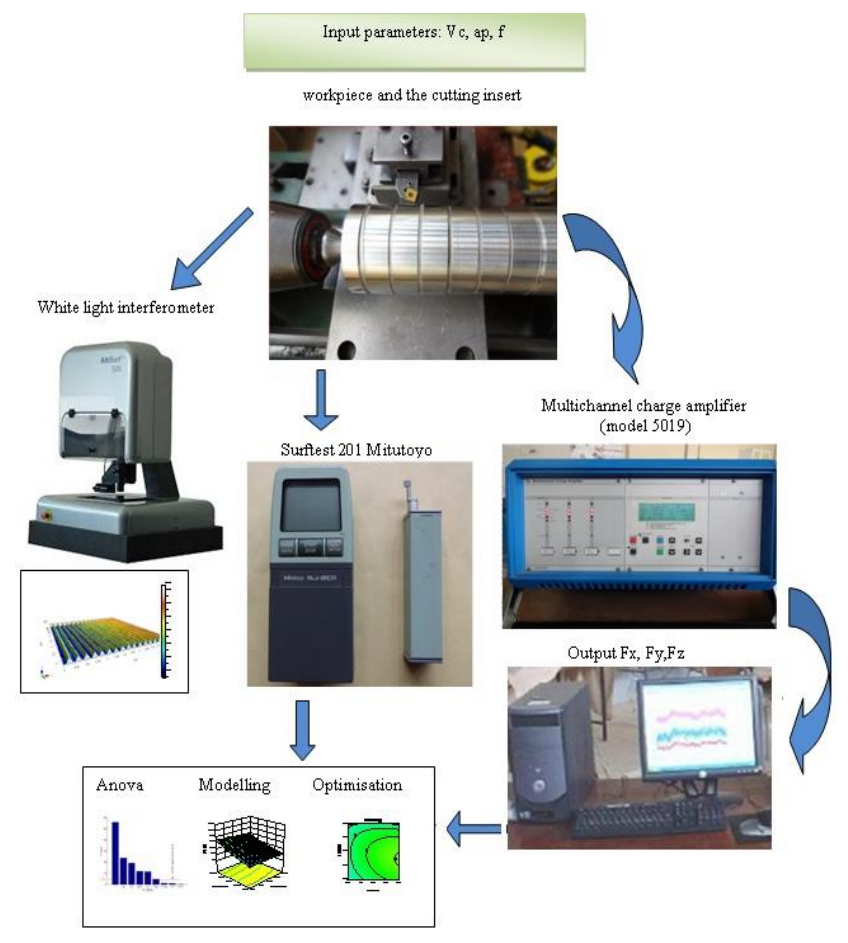

Fig. 1 Schematic diagram of the experimental arrangement

Moreover, and to better visualize the roughness of the machined surfaces, an AltiSurf ${ }^{\circledR} 500$ optical metrology device with a dynamic range of $50 \mathrm{~nm}-300 \mu \mathrm{m}$ was also used. It allows a fine study of the 3D topography of surfaces machined.

The other aspects of machinability such as specific cutting force $K c$ and cutting power $P c$ are calculated regarding the obtained cutting force by application of Eqs. (1) and (2). The material removal rate $(M R R)$ can also be computed using Eq. (3).

$$
\begin{aligned}
& K c=\frac{F c}{S}=\frac{F c}{f \times a p}, \\
& P c=\frac{F c \times V c}{60}, \\
& M R R=V c . f . a p,
\end{aligned}
$$

where: $K c$ is the specific cutting force, $\mathrm{N} / \mathrm{mm}^{2} ; F_{c}$ is the cutting force, $\mathrm{N} ; S$ is the plane area of shear, $\mathrm{mm}^{2} ; P c$ is the cutting power, $\mathrm{W} ; M R R$ is the material removal rate, $\mathrm{cm}^{3} / \mathrm{min} ; f$ is the feed rate; $a p$ is the depth of cut and $V c$ is the cutting speed.

\subsection{Response surface methodology}

The RSM is a combination of statistical and math- 
ematical techniques applied for the development of mathematical models for analysis and optimization. It was favourably implemented for predicting and optimizing cutting parameters by S. Mukherjee et. al. [17] and P. G. Benardos et. al. [18].

In this study, the RSM is applied to obtaining the machinability performances of $R a, F c, K c$, and $P c$ with the three principal machining parameters represented by $f, V c$ and $a p$. The relationship linking the three independent input variables and the output $\varphi$ is given as:

$$
\varphi=f(V c, f, a p)+e_{i j},
$$

where: $\varphi$ is the desired response and $f$ the response surface; $e_{i j}$ is representing the error. The approximation of the output $\varphi$ is performed by a fitted second-order polynomial regression, the quadratic model is expressed as:

$$
\varphi=a_{0}+\sum_{i=1}^{k} a_{i} X_{i}+\sum_{i=1}^{k} a_{i i} X_{i}^{2}+\sum_{i \neq j}^{k} a_{i j} X_{i} X_{j},
$$

where: $a_{o}$ represents a constant; $a_{i}, a_{i i}$, and $a_{i j}$ represent the coefficients of linear; quadratic and cross product terms respectively. $X_{i}, X_{j}$ are the levels assigned to the factors ( $i$ and $j)$.

\subsection{Design of experiments}

The design of experiments is a standard tool to conducting procedures in an optimum way with the objective of investigating the response of the process parameters on the output one. In the present case, L27 $\left(3^{13}\right)$ Taguchi standard rectangular array is adopted as the experimental design procedure for developing an RSM based mathematical approach. This plan possesses 27 rows and 13 columns [19].

Three levels are designated for each factor, and the ranges of the selected one are established according to various preliminary tests. The factors applied in the present investigation and their levels are illustrated in Table 2.

Table 2

Factor levels

\begin{tabular}{|c|c|c|c|}
\hline $\begin{array}{c}\text { Control } \\
\text { parameters }\end{array}$ & Cutting speed & Feed rate & Depth of cut \\
\hline Unit & $\mathrm{m} / \mathrm{min}$ & $\mathrm{mm} / \mathrm{rev}$ & $\mathrm{mm}$ \\
\hline Symbol & $V c$ & $f$ & $a p$ \\
\hline \multirow{3}{*}{ Levels } & 90 & 0.08 & 0.30 \\
\cline { 2 - 4 } & 180 & 0.16 & 0.60 \\
\cline { 2 - 4 } & 350 & 0.24 & 0.90 \\
\hline
\end{tabular}

The experimental parameters and their corresponding responses are displayed in Table 3. Its first column is assigned to $V c$, the second to $f$, and the third to $a p$. The results gathered for $R a$ and $F c$ are displayed in the fourth and fifth columns. The sixth and seventh columns are assigned to $K c$ and $P c$ respectively, while the last column is committed to the metal removal rate $(M R R)$.

\section{Results and discussion}

The influence of the cutting conditions on $R a, F c$, $K c, P c$ and $M R R$ obtained from the turning of ASS
X2CrNi18-09 are displayed in Table 4. They are discussed in the three following paragraphs related to variance analysis, the equation of regression for various responses, and the response surface analysis. The results obtained were analysed using the Design-expert 9 statistical analysis software.

\subsection{Analyse of variance}

Tables 4 to 7 present the results pertaining to the application of ANOVA for $R a, F c, K c$ and $P c$. Moreover, the same tables also show the degrees of freedom (DF), sums of square (SS), mean of square (MS), F-values and Pvalues. The ratio of contribution of the different factors (Cont.\%) and their interactions are also displayed. The purpose is to analyse the impact of the cutting parameters ( $V c$, $f$ and $a p$ ) on the different cutting outputs represented by $R a$, $F c, K c$, and $P c$. The P-value represents a statistical index employed in the ANOVA method. A lower value of the Pvalue indicates the significance of the tested parameter (considered when $\mathrm{P}$-value $<0.05$ ). In this study, cutting parameters that possess a P-value below 0.05 will be considered as significant. Therefore, it seems important to investigate the effect of each cutting condition on the machining characteristics.

ANOVA results displayed in Table 4 show that the feed rate is the most influential factor affecting $R a$. Similar results were reported by Bouzid et. al. [20] and Berkani et. al. [21]. Its contribution achieves $89.69 \%$ while that of the interaction $f^{2}$ is $3.02 \%$. The cutting speed and depth of cut were considered insignificant as their contributions were respectively recorded as $0.41 \%$ and $0.02 \%$.

The impact of the cutting conditions on the cutting force shows that the cutting speed displays a small effect compared to that of both the feed rate and the depth of cut. This is clearly shown in the ANOVA analysis results displayed in Table 5. Moreover, the depth of cut and the feed rate display contribution ratios of $46.46 \%$ and $39.04 \%$ respectively, while that of the cutting speed reaches only $1.52 \%$.

The ANOVA results concerning the specific cutting force and the cutting power are displayed in Tables 6 and 7 respectively. Table 6 clearly shows that the feed rate develops a significant influence on the specific cutting force with a contribution of $38.47 \%$, the depth of cut comes second with $(16.43 \%)$ followed by the cutting speed $(7.89 \%)$. However, and from the results displayed in Table 7, the cutting speed is the most important parameter affecting the cutting power with a contribution of $39.32 \%$. It is followed by the depth of cut with a contribution of $27.50 \%$ and finally the feed rate with $23.18 \%$. The depth of cut with a contribution of $27.50 \%$ and the feed rate with $23.18 \%$ come last.

\subsection{Regression equation for the various responses}

The functional relationships combining the dependent variables $R a, F c, K c$ and $P c$ to the investigated independent variables $V c, f$ and $a p$ are developed and united through the correlation coefficients $R^{2}$ which represent the regression accuracy. The different quadratic models obtained from the statistical analysis are used to predicting the $R a, F c, K c$ and $P c$ in view of the parameters investigated. The models, their determination coefficients and diverse cutting parameters are expressed by Eqs. (6) to (9). 
Table 3

Orthogonal arrays for responses

\begin{tabular}{|c|c|c|c|c|c|c|c|c|}
\hline \multirow{2}{*}{ Test No. } & \multicolumn{3}{|c|}{ Process parameter settings } & \multicolumn{5}{c|}{ Machinability characteristics } \\
\cline { 2 - 9 } & $V c, \mathrm{~m} / \mathrm{min}$ & $f, \mathrm{~mm} / \mathrm{rev}$ & $a p, \mathrm{~mm}$ & $R a, \mu \mathrm{m}$ & $F c, \mathrm{~N}$ & $K c, \mathrm{MPa}$ & $P c, \mathrm{~W}$ & $M R R, \mathrm{~cm}^{3} / \mathrm{min}^{\prime}$ \\
\hline 1 & 90 & 0.08 & 0.3 & 0.82 & 92.31 & 3846.25 & 138.47 & 2.16 \\
\hline 2 & 90 & 0.08 & 0.6 & 0.62 & 131.56 & 2740.83 & 197.34 & 4.32 \\
\hline 3 & 90 & 0.08 & 0.9 & 0.79 & 208.50 & 2895.83 & 312.75 & 6.48 \\
\hline 4 & 90 & 0.16 & 0.3 & 1.60 & 130.60 & 2720.83 & 195.90 & 4.32 \\
\hline 5 & 90 & 0.16 & 0.6 & 1.99 & 214.00 & 2229.17 & 321.00 & 8.64 \\
\hline 6 & 90 & 0.16 & 0.9 & 1.28 & 366.49 & 2545.07 & 549.74 & 12.96 \\
\hline 7 & 90 & 0.24 & 0.3 & 3.63 & 195.69 & 2717.92 & 293.54 & 6.48 \\
\hline 8 & 90 & 0.24 & 0.6 & 3.13 & 330.22 & 2293.19 & 495.33 & 12.96 \\
\hline 9 & 90 & 0.24 & 0.9 & 2.39 & 538.58 & 2493.43 & 807.87 & 19.44 \\
\hline 10 & 180 & 0.08 & 0.3 & 0.66 & 74.50 & 3104.17 & 223.50 & 5.28 \\
\hline 11 & 180 & 0.08 & 0.6 & 1.00 & 147.89 & 3081.04 & 443.67 & 10.56 \\
\hline 12 & 180 & 0.08 & 0.9 & 0.55 & 217.04 & 3014.44 & 651.12 & 15.84 \\
\hline 13 & 180 & 0.16 & 0.3 & 1.24 & 128.37 & 2674.38 & 385.11 & 10.56 \\
\hline 14 & 180 & 0.16 & 0.6 & 1.84 & 217.31 & 2263.65 & 651.93 & 21.12 \\
\hline 15 & 180 & 0.16 & 0.9 & 1.61 & 325.18 & 2258.19 & 975.54 & 31.68 \\
\hline 16 & 180 & 0.24 & 0.3 & 3.32 & 190.84 & 2650.56 & 572.52 & 15.84 \\
\hline 17 & 180 & 0.24 & 0.6 & 3.19 & 346.24 & 2404.44 & 1038.72 & 31.68 \\
\hline 18 & 180 & 0.24 & 0.9 & 3.36 & 497.38 & 2302.69 & 1492.14 & 47.52 \\
\hline 19 & 350 & 0.08 & 0.3 & 0.51 & 90.35 & 3764.58 & 527.04 & 8.4 \\
\hline 20 & 350 & 0.08 & 0.6 & 0.53 & 127.91 & 2664.79 & 746.14 & 16.8 \\
\hline 21 & 350 & 0.08 & 0.9 & 1.36 & 177.13 & 2460.14 & 1033.26 & 25.2 \\
\hline 22 & 350 & 0.16 & 0.3 & 1.81 & 120.68 & 2514.17 & 703.97 & 16.8 \\
\hline 23 & 350 & 0.16 & 0.6 & 1.59 & 170.30 & 1773.96 & 993.42 & 33.6 \\
\hline 24 & 350 & 0.16 & 0.9 & 1.58 & 300.32 & 2085.56 & 1751.87 & 50.4 \\
\hline 25 & 350 & 0.24 & 0.3 & 3.60 & 159.04 & 2208.89 & 927.73 & 25.2 \\
\hline 26 & 350 & 0.24 & 0.6 & 3.19 & 300.03 & 2083.54 & 1750.18 & 50.4 \\
\hline 27 & 350 & 0.24 & 0.9 & 3.58 & 429.37 & 1987.82 & 2504.66 & 75.6 \\
\hline
\end{tabular}

ANOVA table for $R a$

Table 4

\begin{tabular}{|c|c|c|c|c|c|c|c|}
\hline Source & SS & DF & MS & F-value & P-value & Cont. \% & Remark \\
\hline Model & 30.08 & 9 & 3.34 & 41.66 & $<0.0001$ & & Significant \\
\hline$V c$ & 0.13 & 1 & 0.13 & 1.56 & 0.2288 & 0.41 & Insignificant \\
\hline$f$ & 28.20 & 1 & 28.20 & 351.48 & $<0.0001$ & 89.69 & Significant \\
\hline$a p$ & 0.0082 & 1 & 0.0082 & 0.10 & 0.7527 & 0.02 & Insignificant \\
\hline$V c \times f$ & 0.082 & 1 & 0.082 & 1.02 & 0.3269 & 0.26 & Insignificant \\
\hline$V c a p$ & 0.33 & 1 & 0.33 & 4.14 & 0.0579 & 1.04 & Insignificant \\
\hline$f \times a p$ & 0.31 & 1 & 0.31 & 3.87 & 0.0657 & 0.98 & Insignificant \\
\hline$V c^{2}$ & $4.249 \mathrm{e}-08$ & 1 & $4.249 \mathrm{e}-08$ & $5.297 \mathrm{e}-07$ & 0.9994 & 0.00 & Insignificant \\
\hline$f^{2}$ & 0.95 & 1 & 0.95 & 11.80 & 0.0032 & 3.02 & Significant \\
\hline$a p^{2}$ & $4.091 \mathrm{e}-03$ & 1 & $4.091 \mathrm{e}-03$ & 0.051 & 0.8240 & 0.01 & Insignificant \\
\hline Error & 1.36 & 17 & 0.080 & & & & \\
\hline Total & 31.44 & 26 & & & & 100 & \\
\hline
\end{tabular}

Table 5

ANOVA table for $F c$

\begin{tabular}{|c|c|c|c|c|c|c|c|}
\hline Source & SS & DF & MS & F-value & P-value & Cont. \% & Remark \\
\hline Model & $4.017 \mathrm{e}+05$ & 9 & 44632.6 & 285.46 & $<0.0001$ & & Significant \\
\hline$V c$ & 6153.84 & 1 & 6153.84 & 39.36 & $<0.0001$ & 1.52 & Significant \\
\hline$f$ & $1.579 \mathrm{e}+05$ & 1 & $1.579 \mathrm{e}+05$ & 1009.5 & $<0.0001$ & 39.04 & Significant \\
\hline$a p$ & $1.879 \mathrm{e}+05$ & 1 & $1.879 \mathrm{e}+05$ & 1201.7 & $<0.0001$ & 46.46 & Significant \\
\hline$V c \times f$ & 1715.52 & 1 & 1715.52 & 10.97 & 0.0041 & 0.42 & Significant \\
\hline$V c \times a p$ & 2182.85 & 1 & 2182.85 & 13.96 & 0.0016 & 0.54 & Significant \\
\hline$f \times a p$ & 27480.2 & 1 & 27480.2 & 175.75 & $<0.0001$ & 6.79 & Significant \\
\hline$V c^{2}$ & 194.22 & 1 & 194.22 & 1.24 & 0.2806 & 0.04 & Insignificant \\
\hline$f^{2}$ & 1757.65 & 1 & 1757.65 & 11.24 & 0.0038 & 0.43 & Significant \\
\hline$a p^{2}$ & 1364.54 & 1 & 1364.54 & 8.73 & 0.0089 & 0.33 & Significant \\
\hline Error & 2658.04 & 17 & 156.36 & & & & \\
\hline Total & $4.044 \mathrm{e}+05$ & 26 & & & & 100 & \\
\hline
\end{tabular}


ANOVA table for $K c$

Table 6

\begin{tabular}{|c|c|c|c|c|c|c|c|}
\hline Source & SS & DF & MS & F-value & P-value & Cont. \% & Remark \\
\hline Model & $5.367 \mathrm{e}+06$ & 9 & $5.964 \mathrm{e}+05$ & 14.24 & $<0.0001$ & & Significant \\
\hline$V c$ & $4.799 \mathrm{e}+05$ & 1 & $4.799 \mathrm{e}+05$ & 11.46 & 0.0035 & 7.89 & Significant \\
\hline$f$ & $2.339 \mathrm{e}+06$ & 1 & $2.339 \mathrm{e}+06$ & 55.83 & $<0.0001$ & 38.47 & Significant \\
\hline$a p$ & $9.991 \mathrm{e}+05$ & 1 & $9.991 \mathrm{e}+05$ & 23.85 & 0.0001 & 16.43 & Significant \\
\hline$V c \times f$ & 42295.6 & 1 & 42295.6 & 1.01 & 0.3290 & 0.69 & Insignificant \\
\hline$V c \times a p$ & 47557.3 & 1 & 47557.3 & 1.14 & 0.3015 & 0.78 & Insignificant \\
\hline$f \times a p$ & $2.005 \mathrm{e}+05$ & 1 & $2.005 \mathrm{e}+05$ & 4.79 & 0.0429 & 3.29 & Significant \\
\hline$V c^{2}$ & 5973.02 & 1 & 5973.02 & 0.14 & 0.7104 & 0.09 & Insignificant \\
\hline$f^{2}$ & $8.029 \mathrm{e}+05$ & 1 & $8.029 \mathrm{e}+05$ & 19.17 & 0.0004 & 13.20 & Significant \\
\hline$a p^{2}$ & $4.961 \mathrm{e}+05$ & 1 & $4.961 \mathrm{e}+05$ & 11.84 & 0.0031 & 8.16 & Significant \\
\hline$E r r o r$ & $7.121 \mathrm{e}+05$ & 17 & 41885.7 & & & & \\
\hline Total & $6.079 \mathrm{e}+06$ & 26 & & & & 100 & \\
\hline
\end{tabular}

Table 7

ANOVA table for $P c$

\begin{tabular}{|c|c|c|c|c|c|c|c|}
\hline Source & SS & DF & MS & F-value & P-value & Cont. \% & Remark \\
\hline Model & $8.096 \mathrm{e}+06$ & 9 & $8.995 \mathrm{e}+05$ & 125.81 & $<0.0001$ & & Significant \\
\hline$V c$ & $3.231 \mathrm{e}+06$ & 1 & $3.231 \mathrm{e}+06$ & 451.94 & $<0.0001$ & 39.32 & Significant \\
\hline$f$ & $1.905 \mathrm{e}+06$ & 1 & $1.905 \mathrm{e}+06$ & 266.49 & $<0.0001$ & 23.18 & Significant \\
\hline$a p$ & $2.260 \mathrm{e}+06$ & 1 & $2.260 \mathrm{e}+06$ & 316.15 & $<0.0001$ & 27.50 & Significant \\
\hline$V c \times f$ & $3.084 \mathrm{e}+05$ & 1 & $3.084 \mathrm{e}+05$ & 43.14 & $<0.0001$ & 3.75 & Significant \\
\hline$V c \times a p$ & $3.628 \mathrm{e}+05$ & 1 & $3.628 \mathrm{e}+05$ & 50.74 & $<0.0001$ & 4.42 & Significant \\
\hline$f \times a p$ & $3.017 \mathrm{e}+05$ & 1 & $3.017 \mathrm{e}+05$ & 42.20 & $<0.0001$ & 3.67 & Significant \\
\hline$V c^{2}$ & 16712.2 & 1 & 16712.2 & 2.34 & 0.1447 & 0.20 & Insignificant \\
\hline$f^{2}$ & 22367.5 & 1 & 22367.5 & 3.13 & 0.0949 & 0.27 & Insignificant \\
\hline$a p^{2}$ & 11015.8 & 1 & 11015.8 & 1.54 & 0.2314 & 0.13 & Insignificant \\
\hline Error & $1.215 \mathrm{e}+05$ & 17 & 7149.60 & & & & \\
\hline Total & $8.217 \mathrm{e}+06$ & 26 & & & & 100 & \\
\hline
\end{tabular}

$R a=0.96-0.003 V c-1.79 f+0.42 a p+62.06 f^{2}+0.007 V c \times f+0.004 V c \times a p-6.70 f \times a p$, $R^{2}=0.9566$

$F c=65.56+0.416 V c-623.61 f-102.02 a p-0.0003 V c^{2}+2674.30 f^{2} \times a p+1993.92 f \times a p$ $R^{2}=0.9934$

$K c=6255.76+1.51 V c-2482.552 f-5137.25 a p-0.002 V c^{2}+57157.89 f^{2}+3194.8 a p^{2}-$

$-5.62 V c \times f-1.58 V c \times a p+5385.97 f \times a p$

$R^{2}=0.8829$

$$
\begin{aligned}
& P c=688.83-0.26 V c-6258.32 f-1403.89 a p-0.003 V c^{2}-9540.10 f^{2}+476.09 a p^{2}+ \\
& +15.17 V c \times f+4.39 V c \times a p+6606.80 f \times a p \\
& R^{2}=0.9852
\end{aligned}
$$

The probability illustrations of the predicted responses for $R a, F c, K c$ and $P c$ are displayed in Figs. 2, a to $2, \mathrm{~d}$ respectively. The data are found to closely follow a straight line. The null hypothesis indicates that the data distribution law is normal, while the alternative one means it is abnormal. The P-value being greater than that of the degree of significance $(a=0.05)$, the null hypothesis is acknowledged which leads to consider the data as following a normal distribution.

Figs. 3 and 4 compare the results of the measured and predicted results pertaining to $R a$ and $F c$ respectively. The analogy of the results leads to confirm that the models proposed are adequate.

\subsection{Responses surface analysis}

\subsubsection{Surface roughness}

The surface roughness estimated response surfaces with respect to the cutting parameters $V c, f$ and $a p$ are shown in Fig. 5. They show the feed rate as the most important parameter that influences the machined surface. It is noticed that with a low feed rate, the surface machined develops a better quality of surface. The same results have been reported by Z. Hessainia et. al. [22] and M.Y. Noordin et. al. [23]. 


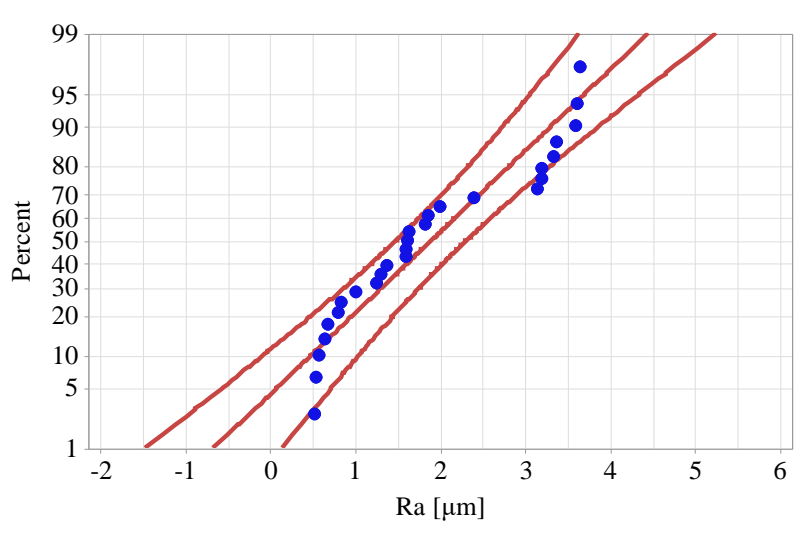

a

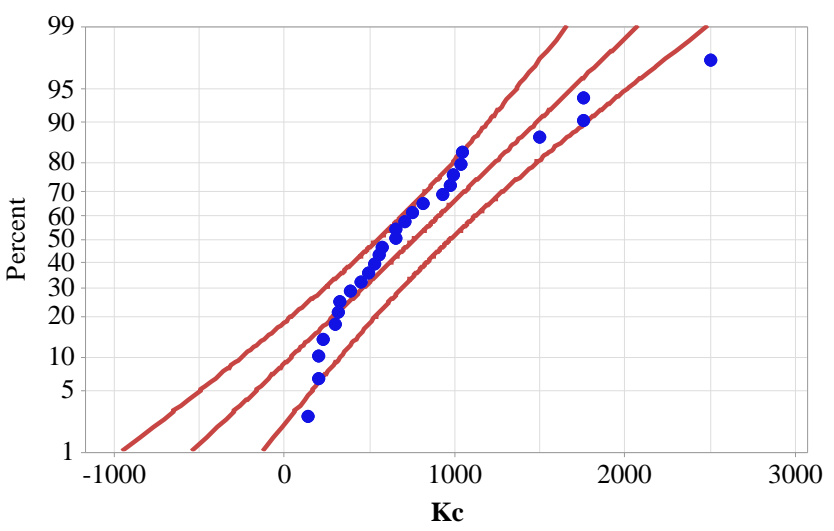

c

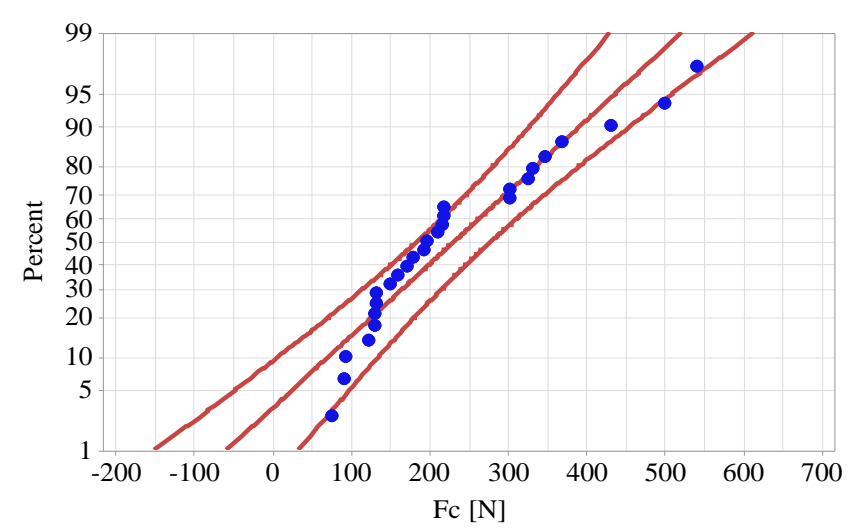

b

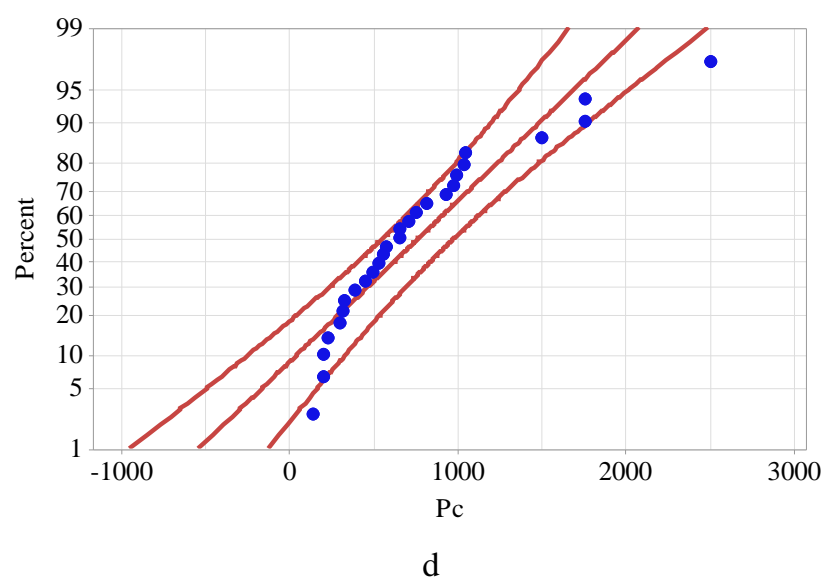

Fig. 2 Normal probability plots: a) $R a$; b) $F c$; c) $K c$; d) $P c$

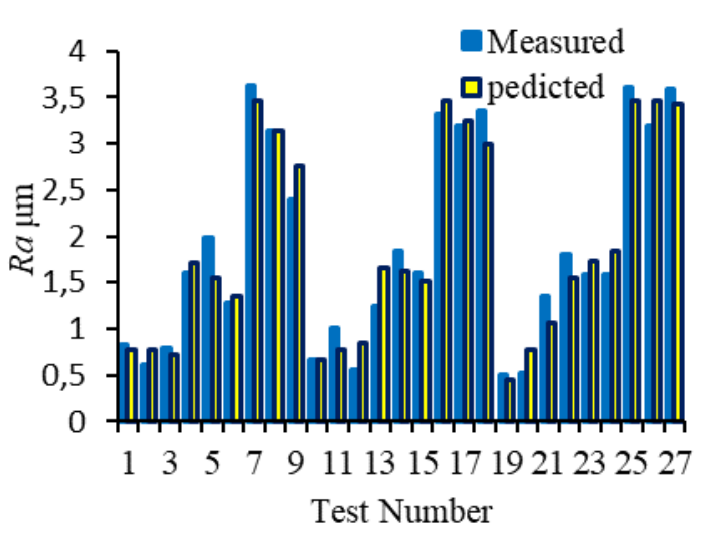

Fig. 3 Comparison between the predicted and measured values for the surface roughness $R a$

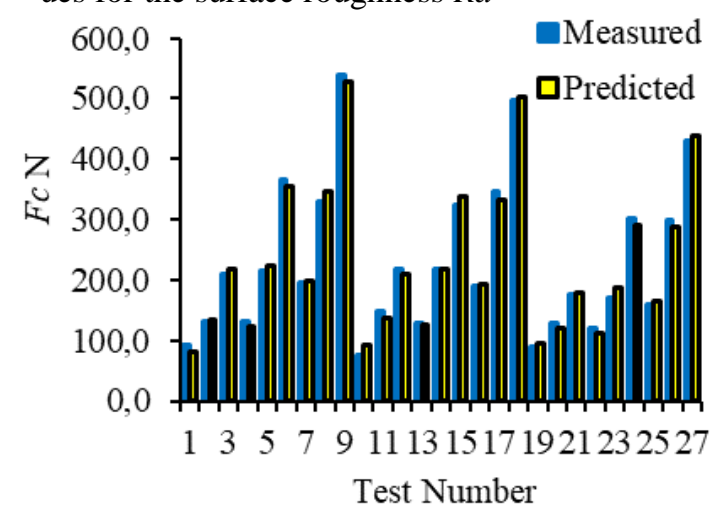

Fig. 4 Comparison between the predicted and measured values for the cutting force $F c$
Low cutting speeds may lead to high surface roughness because of the presence of built up edge (Fig. 6, b) on the rake face, and this is the consequence of the high ductility of ASS as reported by H. Gökkaya [24] and J. Paro et. al. [25].

The increase in surface roughness with that of the cutting speed may be the result of the presence of microwelds on the surface machined because of the high temperatures in the cutting zone and the breaking of BUE (Fig. 6, a). Moreover, this increase may be the consequence of the cutting tool nose whose wears increases thus leading to a poor surface finish as reported by E. Ezugwu et. al. [26]. X2CrNi18-09 great surface roughness results illustrate the high ductility nature of ASS that increases the trend to build a large and unstable BUE, producing a poor surface finish [27].

The continuous friction at the interface tool/chip increases the temperature. Consequently, and because of both the high ductility and deformation modulus of materi-

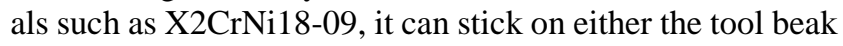
or the rake face generating BUE or micro-welding spots.

\subsubsection{Tangential cutting force}

The 3D surface plot displayed in Fig. 7 exhibits the cutting parameters impact on the cutting force. The variation of this latter with the cutting conditions is linear, increasing with both the feed rate and the depth of cut. This behavior is the result of the increase of the ship section [28]. Furthermore, Fig. 7 shows the feed rate as having a small influence on $F c$ compared to that of the depth of cut, confirming the results developed previously by the ANOVA application. Moreover, the impact of $V c$ on the $F c$ is weak. Indeed, the 
growth of $V c$ contributes to a decrease of $F c$ because of the increase of the cutting zone temperature that results in the mollifying of the workpiece. This allows removing the material using lower $F c$. Similar observations have been reported by A. El-Tamimi et al. [29] and S. Swapnagandha et. al. [30]. They recorded high forces at reduced cutting speeds.

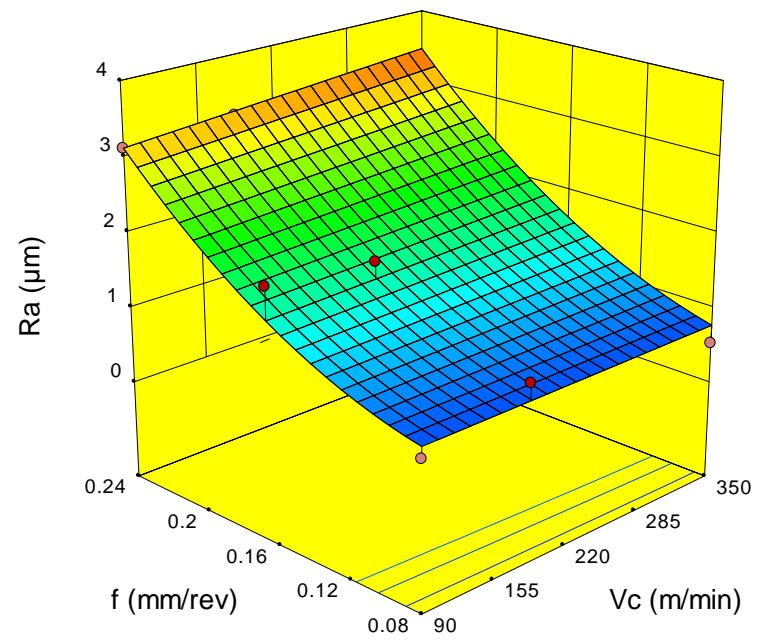

a) $a p=0.6 \mathrm{~mm}$

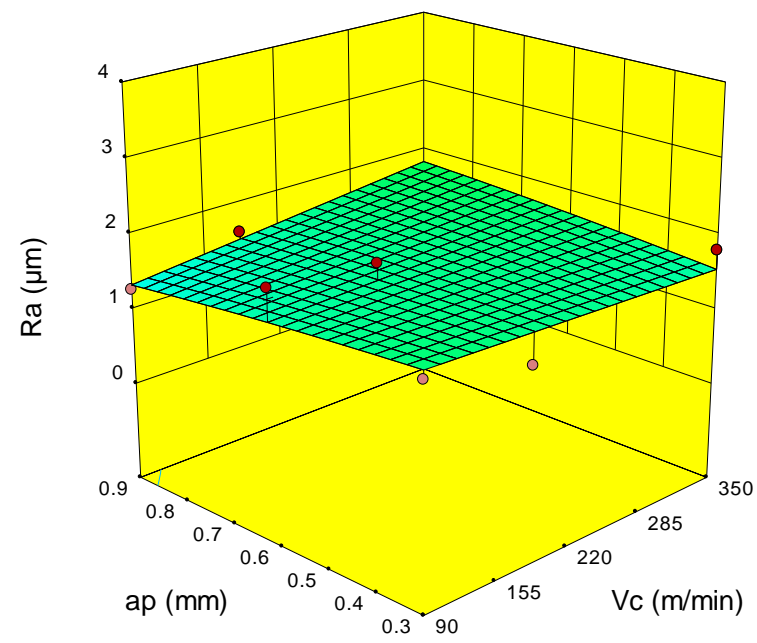

b) $f=0.16 \mathrm{~mm} / \mathrm{rev}$

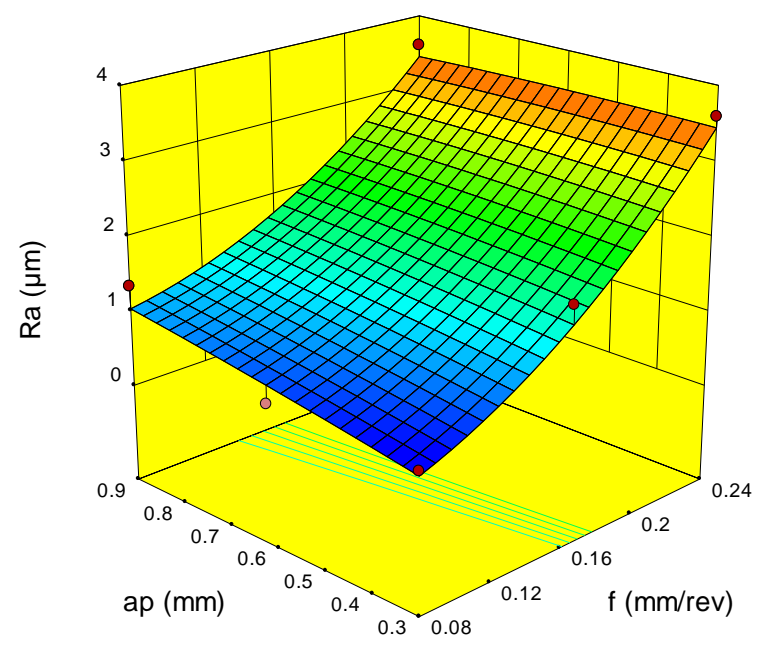

c) $V c=350 \mathrm{~m} / \mathrm{min}$

Fig. 5 Surface and contour plots of $R a$

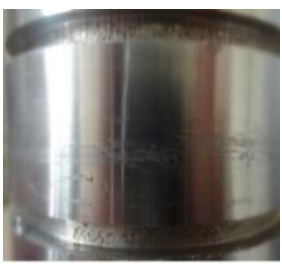

a) Micro-welds

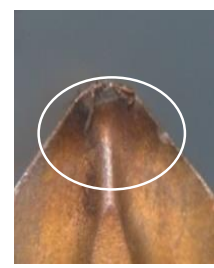

b) Built-up-edge
Fig. 6 Representation of the micro-weld on the machined surface and the built-up edge on the cutting insert

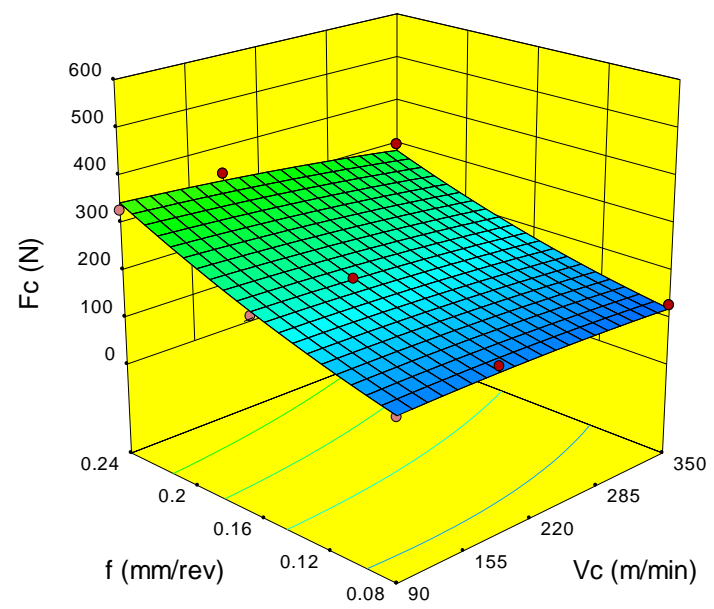

a) $a p=0.6 \mathrm{~mm}$

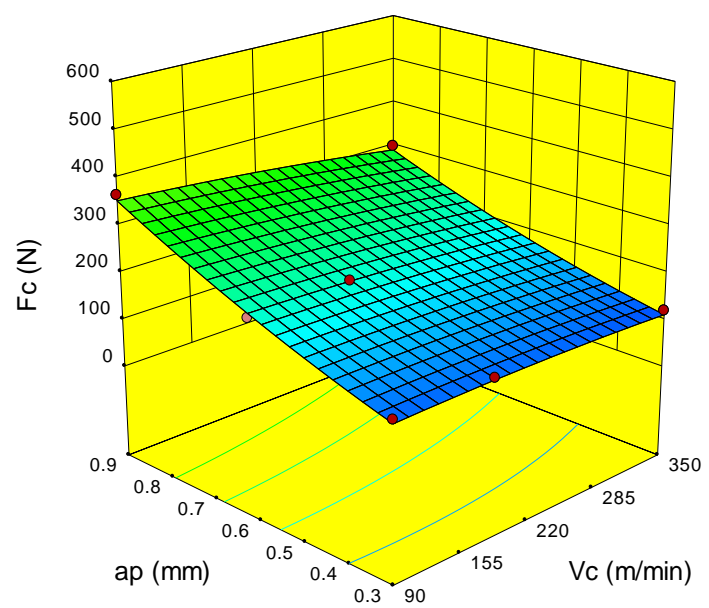

b) $f=0.16 \mathrm{~mm} / \mathrm{rev}$

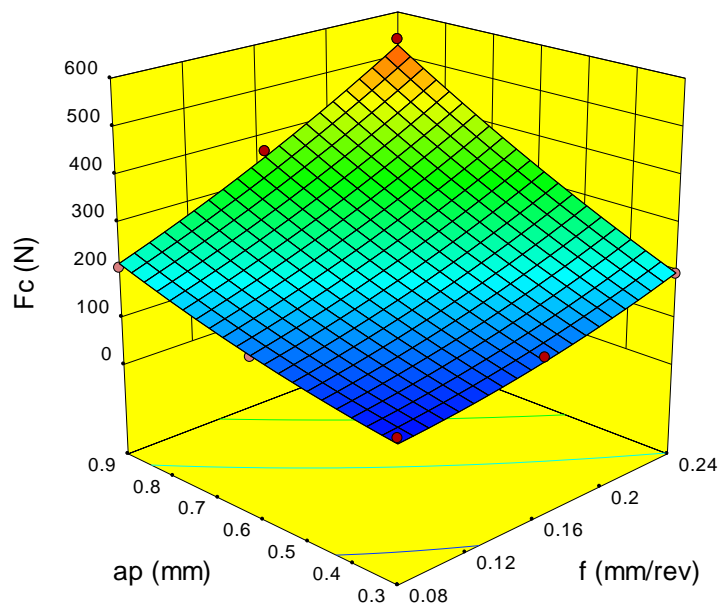

c) $V c=90 \mathrm{~m} / \mathrm{min}$

Fig. 7 Surface and contour plots of $F c$ 
This is a consequence of the chip remaining large times in the tool rake face that leads to an increase of the contact tool-chip length which in turn raises the friction between ends of the chip with the tool resulting in higher forces.

\subsubsection{Power and specific cutting force}

The variation of the power with the various cutting parameters (Fig. 8) shows that the power increases with the diverse cutting parameters. It looks clear from the surface plots that $a p$ is the preponderant parameter affecting $P c$ as it raises with the tangential force.

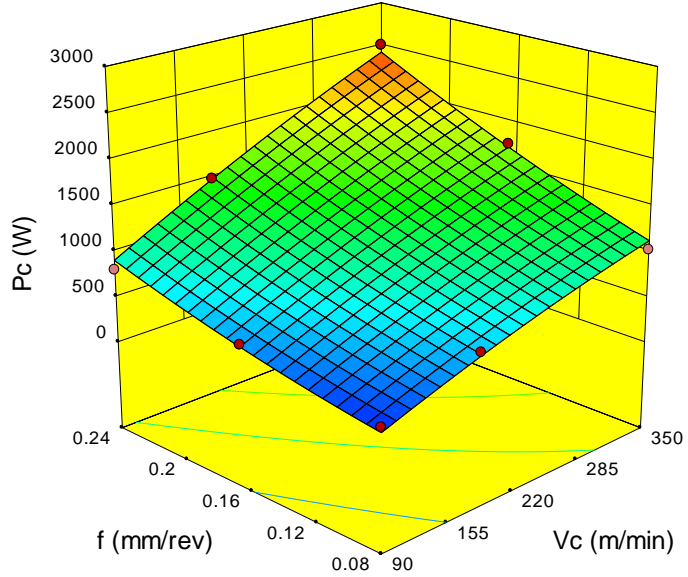

a) $a p=0.9 \mathrm{~mm}$

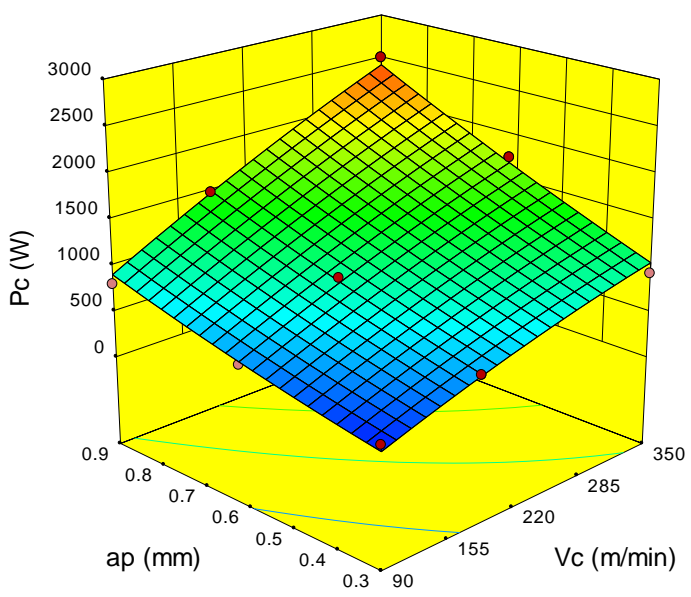

b) $f=0.24 \mathrm{~mm} / \mathrm{rev}$

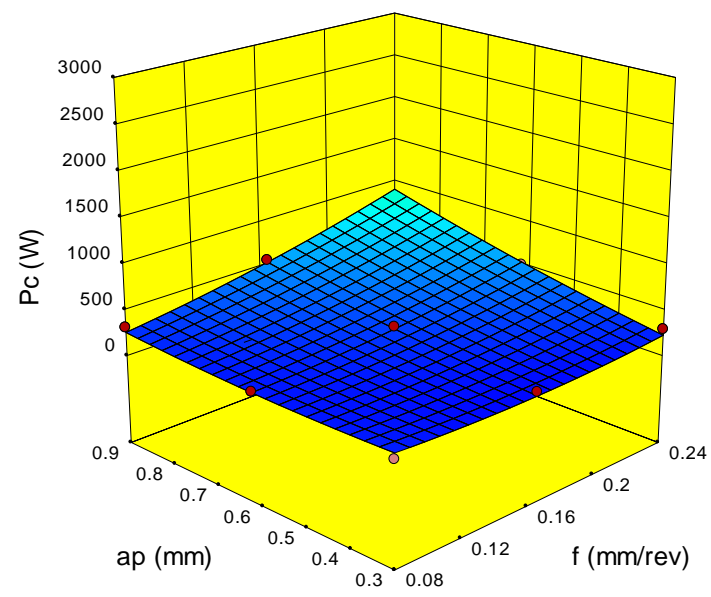

c) $V c=90 \mathrm{~m} / \mathrm{min}$

Fig. 8 Surface and contour plots of $P C$
The impact of the considered cutting parameters $V c, f$ and $a p$ on $K c$ is displayed in Fig. 9. It may be noticed that the feed rate affects considerably $K c$ as it reduces while $f$ increases as reported by J. Kaczmarek [30]. Moreover, the growth of the feed rate generates higher friction between the material being removed and the cutting tool.

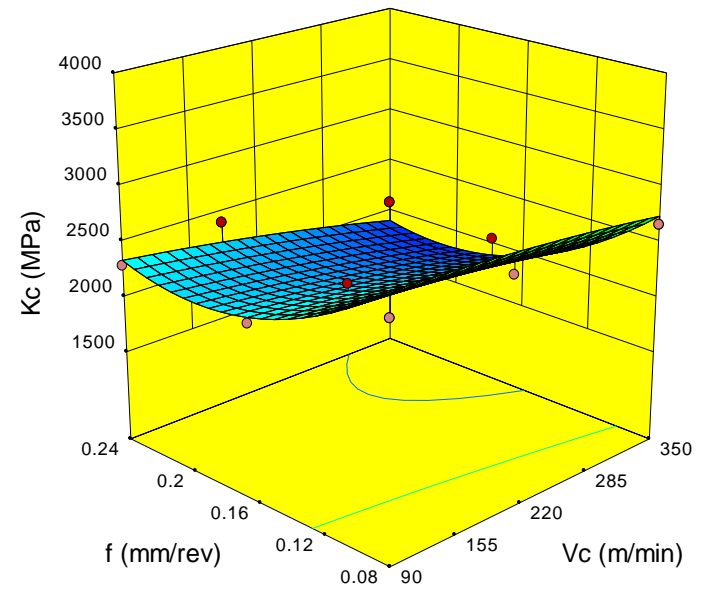

a) $a p=0.6 \mathrm{~mm}$

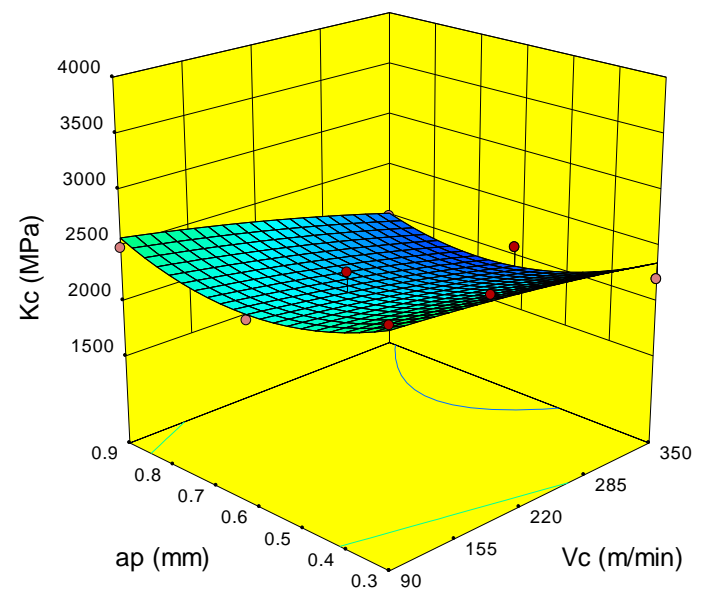

b) $f=0.24 \mathrm{~mm} / \mathrm{rev}$

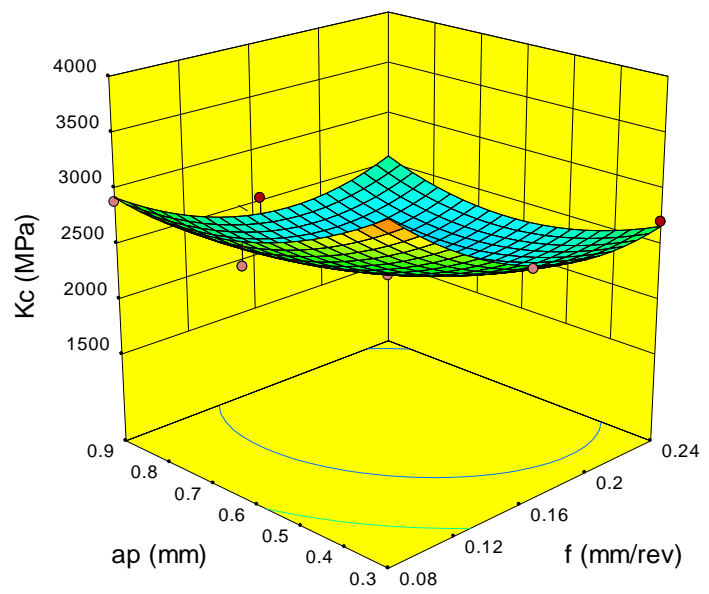

c) $V c=90 \mathrm{~m} / \mathrm{min}$

Fig. 9 Surface and contour plots of $K c$

It looks clear from the analysis illustrated in Fig.9 that higher cutting speeds along with high feed rates lead to a reduction of the cutting force and consequently that of the specific cutting force. This is the result of the heat generation produced by the tool-chip friction within the range of the cutting speed, and is the consequence of the low thermal 
conductivity of the steel X2CrNi18-09 represented in Table 1 .

\subsubsection{Material removal rate}

Fig. 10 represents the variation of $M R R$ expressed in Eq. (3) at different cutting conditions. The $M R R$ is seen increasing with the cutting parameters $V c, f$ and $a p$. In this case, the ap is the most important parameter affecting $M R R$, followed by the feed rate and finally the cutting speed. The depth of cut being generally limited by the couple of toolworkpiece, its reaching the highest permitted level leads the feed rate to become the $M M R$ most influencing parameter.

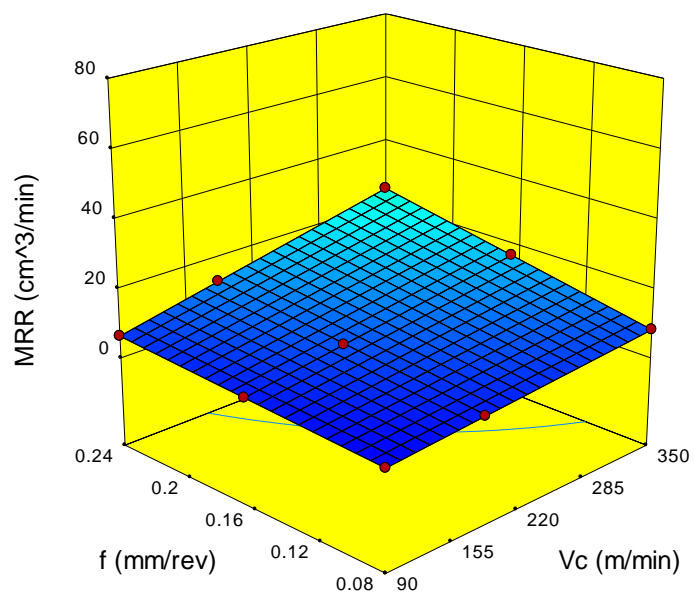

a) $a p=0.3 \mathrm{~mm}$

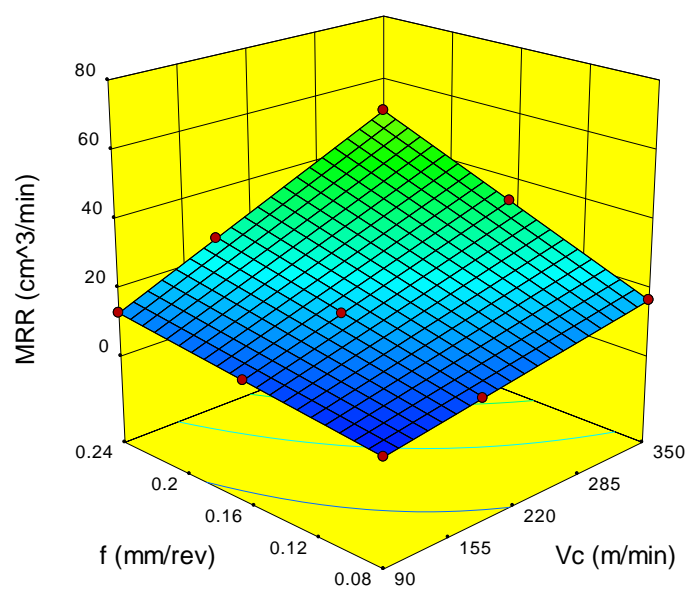

b) $a p=0.6 \mathrm{~mm}$

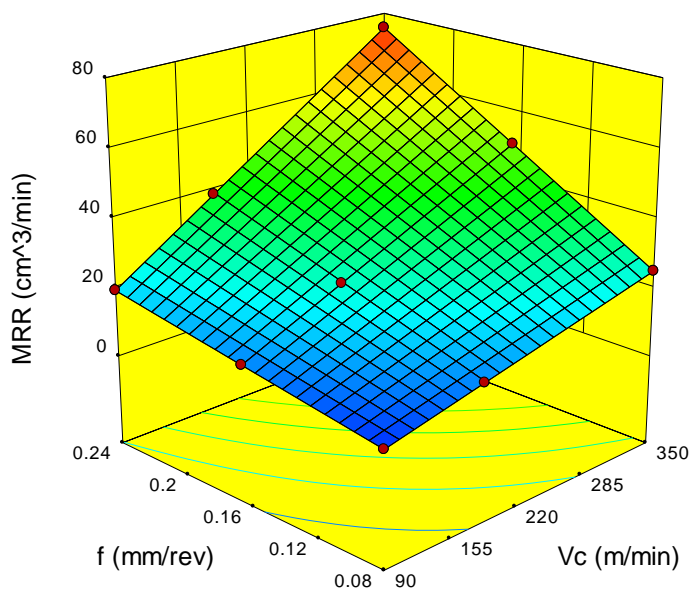

c) $a p=0.9 \mathrm{~m}$

Fig. 10 Surface and contour plots for $M R R$

\section{Confirmation tests}

In order to validate the mathematical models obtained through the application of Eqs. (6) to (9), confirmation tests were performed for $R a, F c, K c$ and $P c$. The cutting parameters adopted in the confirmation tests of turning are displayed in Table 8 while the results gathered are shown in Fig.11 where a comparison of the predicted values resulting from the application of the model developed and the experimental data is performed.

Table 8

Cutting conditions used in turning confirmation tests

\begin{tabular}{|c|c|c|c|}
\hline Test $\mathrm{N}$ & $V c, \mathrm{~m} / \mathrm{min}$ & $F, \mathrm{~mm} / \mathrm{rev}$ & $a p, \mathrm{~mm}$ \\
\hline $\mathrm{T} 1$ & 160 & 0.08 & 0.3 \\
\hline $\mathrm{T} 2$ & 230 & 0.08 & 0.3 \\
\hline $\mathrm{T} 3$ & 230 & 0.16 & 0.3 \\
\hline
\end{tabular}

The results displayed in Fig. 11 show the predicted error varying between a maximum of $4.48 \%$ and a minimum of $0.45 \%$ for $R a$. The same errors are found to vary between $7.86 \%$ and $2.84 \%$ for $F c, 6.93 \%$ and $0.35 \%$ for $K c$, and $14.06 \%$ and $3.48 \%$ for $P c$. Consequently, the Eqs. applied (6), (7), (8) and (9) can be considered as correlating the development of $R a, F c, K c$ and $P c$ with the cutting parameters with a reasonable degree of approximation (Fig. 11).

In addition to the results concerning the surface roughness shown in Fig. 11, a non-contact three-dimensional white-light interferometer (Altisurf 500) with a sensor having a dynamic range of $50 \mathrm{~nm}-300 \mu \mathrm{m}$ was employed to investigate the surface topography.

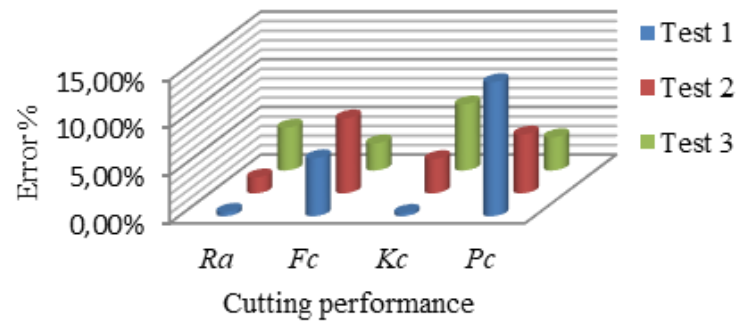

Fig. 11 Errors between predicted and experimental results

Fig. 12 shows the 3D surface roughness profiles after machining with various cutting speeds and feed rates. For a high feed rate corresponding to $f=0.20 \mathrm{~mm} / \mathrm{rev}$, the shape of the profile is periodical with well-defined peaks and valleys. The spacing between two peaks is found equal to the feed rate (Fig. 12, b and c). Similar results were reported by [32-35] where the surface roughness $R a$ is greater than that of the surfaces machined with low feed rates (Fig. 12, a and d) where corrugations and surface roughness $R a$ are small.

\section{Multi response optimizations}

The desirability function is extensively used in the industry for the optimization of multiple response processes. Diverse desirability functions were proposed by G. Derringer and R. Suich [36].

The present investigation applied the RSM desirability function optimization for $R a, F c, K c, P c$ and $M R R$. The main goal was to finding out the optimal values for the cutting parameters that minimize the surface roughness (quality optimization) while simultaneously maximize $M R R$ 


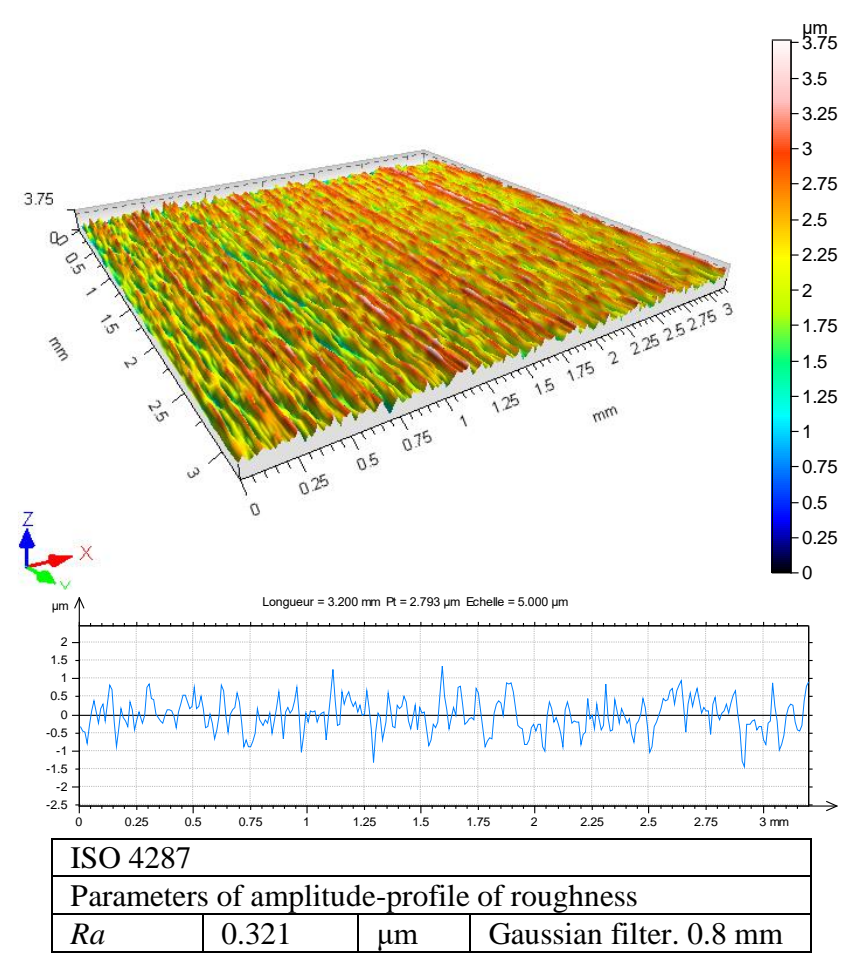

a) $V c=140 \mathrm{~m} / \mathrm{min}, f=0.08 \mathrm{~mm} / \mathrm{rev}, a p=0.3 \mathrm{~mm}$
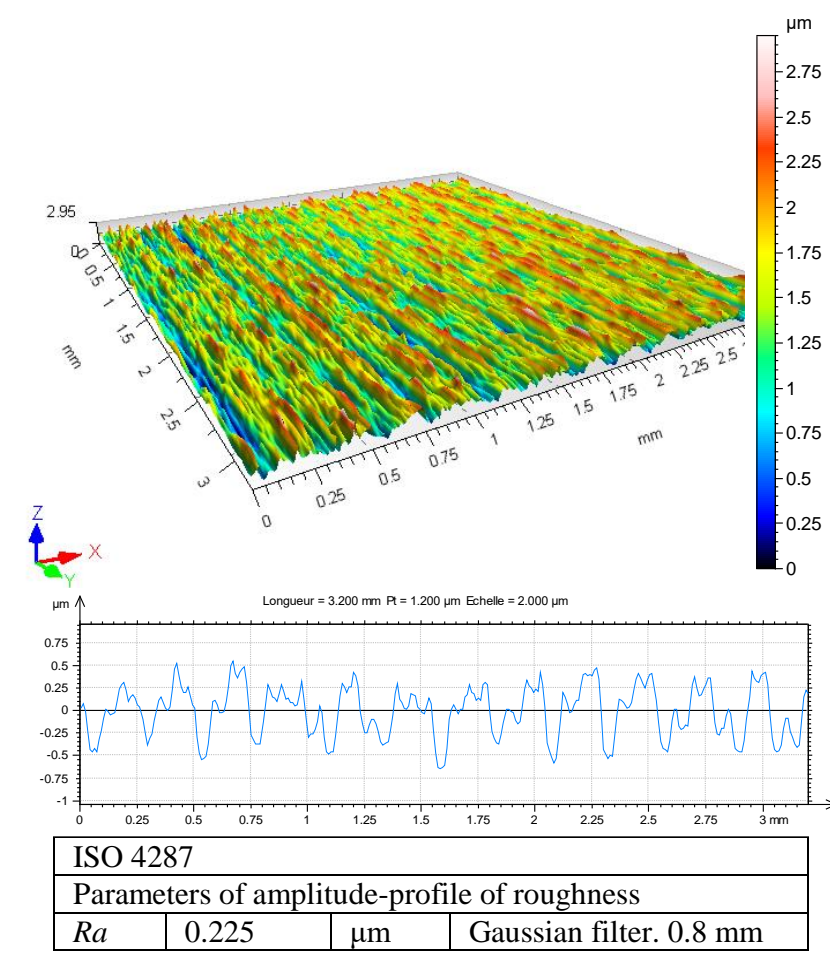

c) $V c=280 \mathrm{~m} / \mathrm{min}, f=0.08 \mathrm{~mm} / \mathrm{rev}, a p=0.3 \mathrm{~mm}$

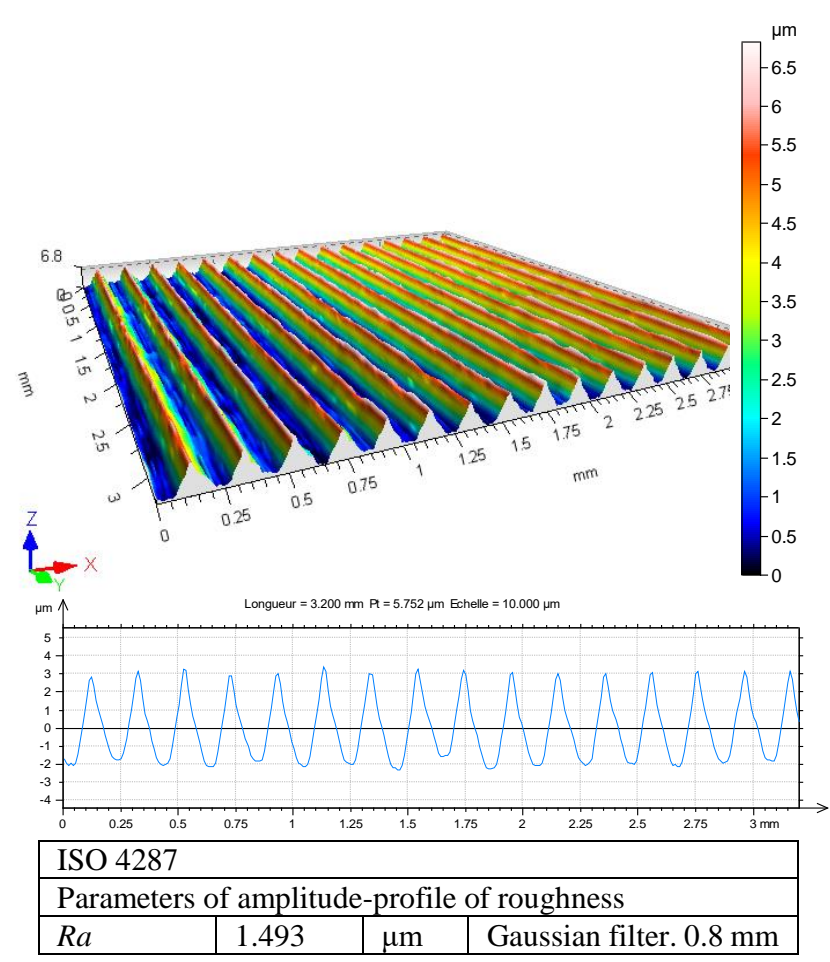

b) $V c=140 \mathrm{~m} / \mathrm{min}, f=0.2 \mathrm{~mm} / \mathrm{rev}, a p=0.3 \mathrm{~mm}$

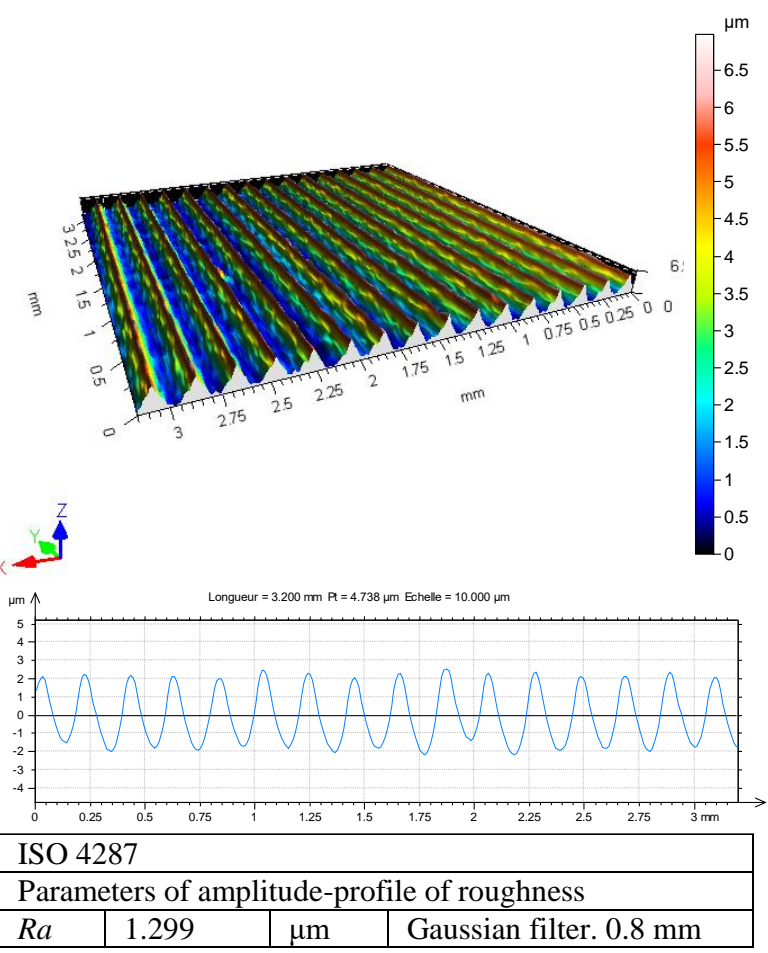

d) $V c=280 \mathrm{~m} / \mathrm{min}, f=0.2 \mathrm{~mm} / \mathrm{rev}, a p=0.3 \mathrm{~mm}$

Fig. 12 2D and 3D surface roughness

(Productivity optimization). Table 10 shows the optimization constraints for the above-cited cutting parameters.

As displayed in Table 9, three configurations are investigated. The first one concerns the quality optimization recommended for achieving an improved surface quality and reduced productivity with a desirability of (1). The second configuration is represented by the optimization of productivity that should drive to boost productivity but and unfortunately loses surface quality with a desirability of (1). The last configuration deals with an arrangement between the surface quality and the productivity, and this is what essentially interests the actual research as it puts together best surface quality and maximum productivity. With this goal in mind, the optimum cutting parameters obtained are defined by a cutting speed of $350 \mathrm{~m} / \mathrm{min}$, a feed rate of 0.088 $\mathrm{mm} / \mathrm{rev}$ and a depth of cut of $0.9 \mathrm{~mm}$. The optimized parameters $R a, F c$ and $M R R$ are equal to $1.097 \mu \mathrm{m}, 187.537 \mathrm{~N}$, and $27.577 \mathrm{~cm}^{3} / \mathrm{min}$ respectively. Table 10 summarizes the results for each type of optimization.

The graphic ramp functions for $R a$ and $M R R$ overall desirability is illustrated in Fig. 13 with the red dots 
Table 9

Constraints for optimization of cutting conditions

\begin{tabular}{|c|c|c|c|c|c|c|}
\hline \multirow{2}{*}{ Name } & \multirow{2}{*}{ Goal } & \multirow{2}{*}{ Lower Limit } & \multirow{2}{*}{ Upper Limit } & \multicolumn{3}{|c|}{ Importance } \\
\cline { 5 - 7 } & & & Quality & Productivity & Combined \\
\hline$V c, \mathrm{~m} / \mathrm{min}$ & in range & 90 & 350 & 3 & 3 & 3 \\
\hline$f, \mathrm{~mm} / \mathrm{rev}$ & in range & 0.08 & 0.24 & 3 & 3 & 3 \\
\hline$a p, \mathrm{~mm}$ & in range & 0.3 & 0.9 & 3 & 3 & 3 \\
\hline$R a, \mu \mathrm{m}$ & Minimize & 0.51 & 3.63 & $\mathbf{5}$ & - & $\mathbf{5}$ \\
\hline$F c, \mathrm{~N}$ & Minimize & 74.5 & 538.58 & - & - & $\mathbf{5}$ \\
\hline$M R R, \mathrm{~cm}^{3} / \mathrm{min}$ & Maximize & 25.12 & 452.16 & - & $\mathbf{5}$ & $\mathbf{5}$ \\
\hline
\end{tabular}

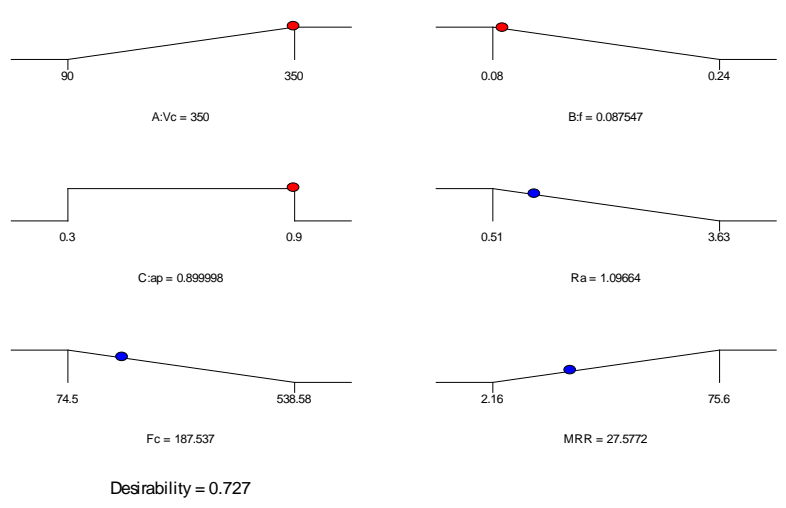

Fig. 13 Ramp function graph (Multi-objective)

Table 10

Optimization results

\begin{tabular}{|c|c|c|c|c|c|c|c|}
\cline { 2 - 7 } \multicolumn{1}{c|}{} & \multicolumn{3}{c|}{$\begin{array}{c}\text { Cutting } \\
\text { parameters }\end{array}$} & \multicolumn{3}{c|}{ Responses } & \multicolumn{1}{c}{} \\
\hline Optimization & $V c$ & $f$ & ap & $R a$ & $F c$ & $M R R$ & Desirability \\
\hline Productivity & 350 & 0.24 & 0.9 & - & - & 75.60 & 1 \\
\hline Quality & 350 & 0.08 & 0.3 & 0.451 & - & - & 1 \\
\hline Combined & 350 & 0.088 & 0.9 & 1.097 & 187.52 & 27.557 & 0.727 \\
\hline
\end{tabular}

shown for the cutting velocity, the feed rate and the depth of cut curves representing the optima. The optima corresponding response for $R a$ and $M R R$ are described by the blue dots.

The contour graphs presented in Fig. 14 represent both the cutting speed and the feed rate optima. Moreover, they show the development of the opportunity value for $R a$ and $M R R$ with that of the number of revolutions and feed spindle.

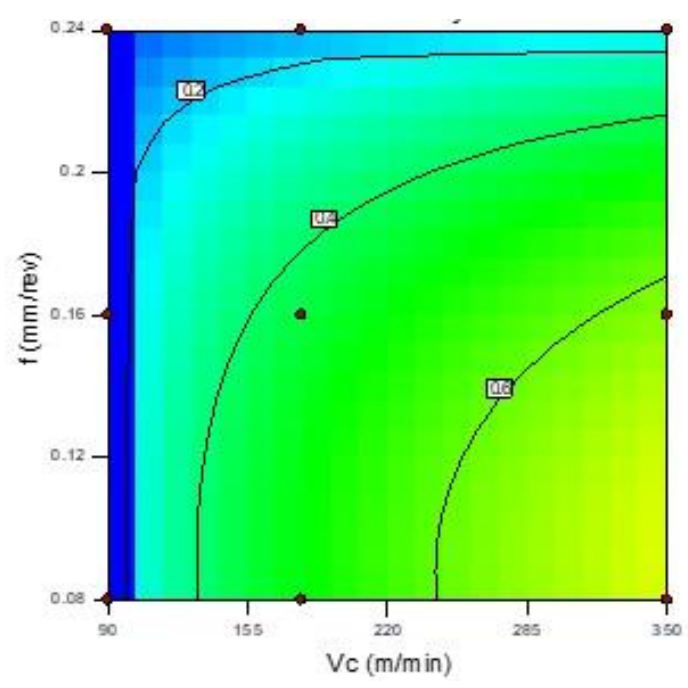

Fig. 14 Desirability contour (multi-objective)
Using bars, Fig. 15 plots the desirability for the cutting conditions and the responses together with a combined desirability of 0.727 .

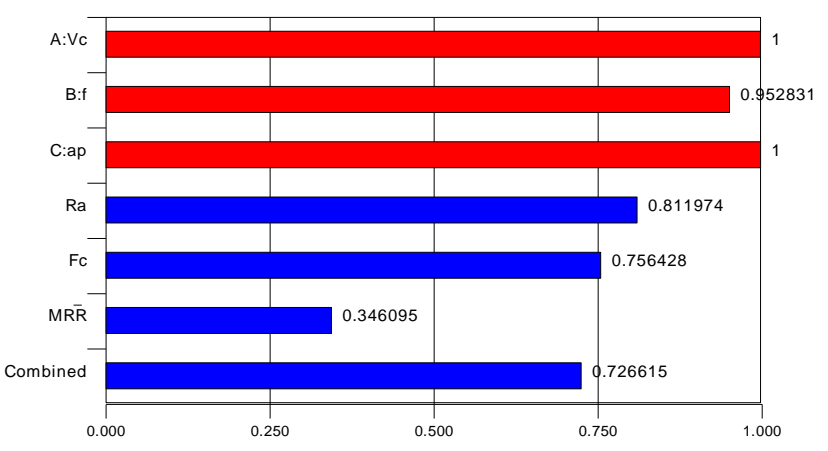

Fig. 15 Bar graph of desirability (multi-objective)

\section{Evolution of flank wear and roughness as a function of time}

Flank wear $V B$ is an important measurement of cutting tools life. It is usually seen at the front face of the cutting inserts.

The investigation of the evolution of the flank wear and surface roughness $R a$ as a function of time needed carrying out long-term tests on workpiece of length $L=400 \mathrm{~mm}$ with the same feed rate, the same depth of cut and different cutting speeds.

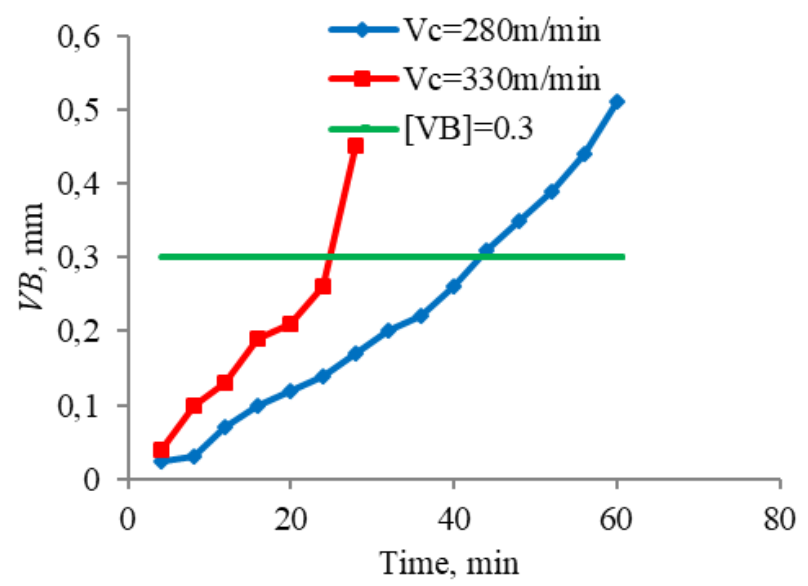

Fig. 16 Evolution of the flank wears as a function of time

Fig. 16 displays the flank wear $V B$ in terms of the machining time for the two cutting speeds $V c=280 \mathrm{~m} / \mathrm{min}$ and $V c=330 \mathrm{~m} / \mathrm{min}$. It shows that the increase of the cutting speed leads to that of the flank wear. At $V c=280 \mathrm{~m} / \mathrm{min}$, the chip obtained is found to be long and the developed wear exhibits a band on the surface of the tool (Fig. 17). The tool life of the carbide GC 2015 is found to last 44 minutes. 
At $V c=330 \mathrm{~m} / \mathrm{min}$, the carbide coating GC2015 detaches quickly due to the high temperature in the cutting area (Fig. 18). A tool life of 24 minutes was recorded for the GC2015 carbide at an admissible wear of $V B=0.3 \mathrm{~mm}$.
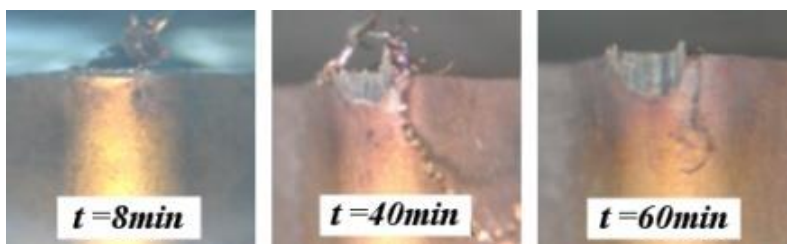

Fig. 17 Evolution of wear $V B$ at $V c=280 \mathrm{~m} / \mathrm{min}, f=0.08$ $\mathrm{mm} / \mathrm{rev}$ and $a p=0.2 \mathrm{~mm}$
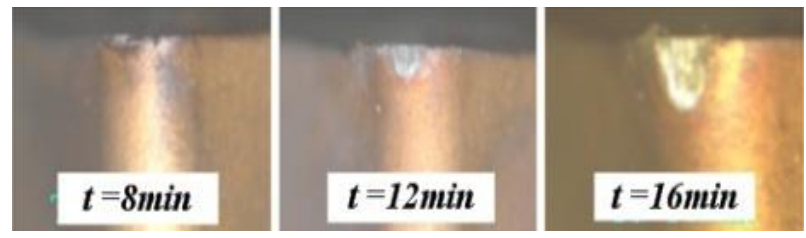

Fig. 18 Evolution of flank wear $V B$ at $V c=330 \mathrm{~m} / \mathrm{min}$, $f=0.08 \mathrm{~mm} / \mathrm{rev}$ and $a p=0.2 \mathrm{~mm}$

Fig. 19 shows the evolution of the machined surface roughness in terms of cutting time for the GC2015. Roughness curves are found to be almost identical to those of the flank wear, and this shows the relationship of this latter to the cutting time. As the machining time increases, the friction also increases giving birth to the diverse wear mechanisms that lead to the degradation of the machined surface.

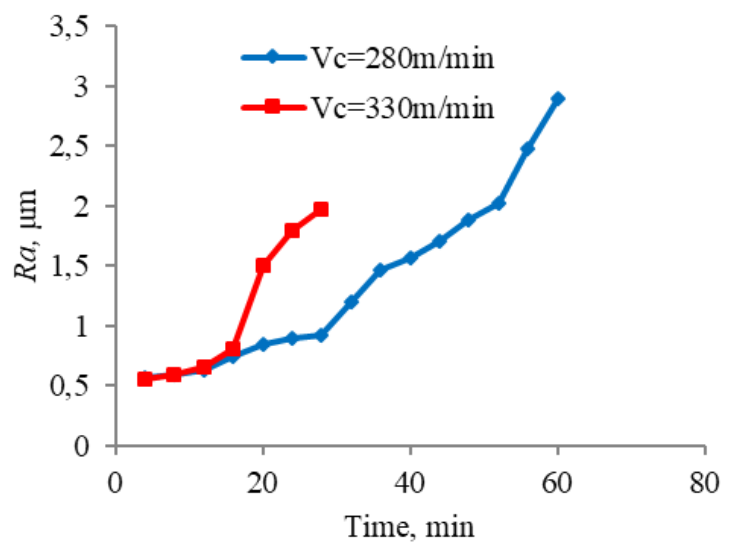

Fig. 19 Evolution of the roughness as a function of time

At the cutting speed $V c=280 \mathrm{~m} / \mathrm{min}$, the increase in flank wear introduces a deterioration of the surface condition leading to the sticking of the micro-welds on the machined surface of the workpiece (Fig. 6). For the admissible flank wear $V B=0.3 \mathrm{~mm}$, the tool life of GC2015 is noticed at $t=44 \mathrm{~min}$ and $R a=1.7 \mu \mathrm{m}$. At the end of the machining operation that corresponds to a time of 60 minutes and a flank wear of $0.51 \mathrm{~mm}$, the roughness is found to be $R a=2.90 \mu \mathrm{m}$.

At $V c=330 \mathrm{~m} / \mathrm{min}$, the increase in flank wear leads to an increase in roughness criteria. For a flank wear of 0.3 $\mathrm{mm}$ (which corresponds to a tool life $t=24 \mathrm{~min}$ ), the $R a$ value is $1.8 \mu \mathrm{m}$. At the end of the machining (for a time of 28 minutes) and a flank wear of $0.45 \mathrm{~mm}, R a$ reaches $1.97 \mu \mathrm{m}$.

\section{Conclusions}

The optimization of the machinability and part quality has been investigated for the coated carbide tools turning of the $\mathrm{X} 2 \mathrm{CrNi18-09}$ stainless steel. The results achieved led to the following conclusions:

The analysis proved that the feed rate is the most important parameter influencing the surface roughness with an $89.69 \%$ contribution in the total model variability. The cutting speed and the depth of cut follow with contributions of $0.41 \%$ and $0.02 \%$ respectively. The cutting force was highly affected by the depth of cut. Its contribution was $46.46 \%$ followed by the feed rate $(39.04 \%)$.

The cutting force was highly influenced by the depth of cut. Its contribution was $46.46 \%$ followed by the feed rate $(39.04 \%)$. The cutting speed develops a small contribution $(1.52 \%)$. Initially, the cutting force increases with both the depth of cut and the feed rate to decrease later when the cutting speed increases. This reduction is probably a consequence of the development of the temperature in the cutting zone that leads to the mollifying of the workpiece.

The feed rate develops the highest influence on the specific cutting force achieved with a contribution of $38.47 \%$ followed by the depth of cut $(16.43 \%)$ and finally the cutting speed $(7.89 \%)$. At high cutting speeds and low feed rate, the cutting force is found smaller which leads to the reduction of the specific cutting force.

The cutting speed is the parameter most affecting the power with a contribution of $39.32 \%$, while the depth of cut develops $27.50 \%$ and the feed rate $23.18 \%$. The development of the parameters under investigation leads that of the cutting power required to perform the machining operations.

The confirmation tests demonstrate that the error related to surface roughness $R a$ reaches a maximum of $4.48 \%$ and a minimum of $0.45 \%$ for the cutting force $F c$ optima of $7.86 \%$ and $2.84 \%$, the specific cutting force $K c$ optima of $6.93 \%$ and $0.35 \%$, and for the cutting power $P c$ optima of $14.06 \%$ and $3.48 \%$.

The response optimization shows that a maximum quality leads to an important productivity loss and viceversa. To overcome this problem, a compromise is required between part quality and productivity. The optimal cutting parameters that combine best quality along with best productivity are found to be $V c=350 \mathrm{~m} / \mathrm{min}, f=0.088$ $\mathrm{mm} / \mathrm{rev}$, and $a p=0.9 \mathrm{~mm}$.

The flank wear of the CVD-coated carbide tool (GC2015).is found to increase with both cutting speed and cutting time. The results show that a higher tool life $(t=44$ min witch give a roughness $R a=1.70 \mu \mathrm{m}$ ) is observed at $V c=280 \mathrm{~m} / \mathrm{min}, f=0.08 \mathrm{~mm} / \mathrm{rev}$ and $a p=0.2 \mathrm{~mm}$.

At low cutting speeds, the formation of micro weld is noticed, resulting in a deterioration of the roughness of the workpiece surface.

The influence of the feed rate on surface roughness can be visualised by the $3 \mathrm{D}$ topographic map of the machined surface.

\section{References}

1. Korkut, I.; Kasap, M.; Ciftci, I.; Seker, U. 2004. Determination of optimum cutting parameters during machining of AISI 304 austenitic stainless steel, Materials \& Design 25(4): 303-305. 
http://dx.doi.org/10.1016/j.matdes.2003.10.011

2. Nayak, S. K.; Patro, J. K.; Dewangan, S.; Gangopadhyay, S. 2014. Multi-objective optimization of machining parameters during dry turning of AISI 304 austenitic stainless steel using grey relational analysis, Procedia Materials Science 6: 701-708. http://dx.doi.org/10.1016/j.mspro.2014.07.086.

3. Hamdan, A.; Sarhan, A. A. D.; Hamdi, M. 2012. An optimization method of the machining parameters in high-speed machining of stainless steel using coated carbide tool for best surface finish, Int. J. Adv. Manuf. Technol. 58: 81-91. http://dx.doi.org/10.1007/s00170-011-3392-5.

4. Philip Selvaraj, D.; Chandramohan, P.; Mohanraj, M. 2014. Optimization of surface roughness, cutting force and tool wear of nitrogen alloyed duplex stainless steel in a dry turning process using Taguchi method, measurement, Journal of the International Measurement 49: 205-215.

http://dx.doi.org/10.1016/j.measurement.2013.11.037.

5. Xavior, M. A.; Adithan, M. 2009. Determining the influence of cutting fluids on tool wear and surface roughness during turning of AISI 304 austenitic stainless steel, Journal of Materials Processing Technology 209(2): 900909. http://dx.doi.org/10.1016/j.jmatprotec.2008.02.068.

6. Kalidass, S.; Palanisamy, P.; Muthukumaran, V.2 013. Prediction and optimisation of tool wear for end milling operation using artificial neural networks and simulated annealing algorithm, International Journal of Machining and Machinability of Materials 14: 142-164. http://dx.doi.org/ 10.1504/IJMMM.2013.055734.

7. Maheswara, Rao Ch.; Venkatasubbaiah. K. 2016. Optimization of surface roughness in CNC turning using Taguchi method and ANOVA, International Journal of Advanced Science and Technology 93: 1-14. http://dx.doi.org/10.14257/ijast.2016.93.01.

8. Kulkarni, A.; Joshi, G.; Sargade, V. G. 2013. Design optimization of cutting parameters for turning of AISI 304 austenitic stainless steel using Taguchi method, Indian Journal of Engineering and Materials Sciences 20:252-258.

http://nopr.niscair.res.in/handle/123456789/20960.

9. Chinchanikar, S.; Choudhury, S. K. 2015. Machining of hardened steel - Experimental investigations, performance modeling and cooling techniques: A review, International Journal of Machine Tools \& Manufacture 8995-109. http://dx.doi.org/10.1016/j.ijmachtools.2014.11.002.

10. Kribes, N.; Hessainia, Z.; Yallese, M. A,; Ouelaa, N. 2012. Statistical analysis of surface roughness by design experiments in hard turnning, Machanika 18(5): 605611. http://de.doi.org/10.5755/j01.mech.18.5.2704.

11. Philip Selvaraj, D.; Chandramohan, P. 2010. Optimization of surface roughness of AISI 304 austenitic stainless steel in dry turning operation using Taguchi design method, Journal of Engineering Science and Technology 5(3): 3 293-301.

http://jestec.taylors.edu.my/Vol\%205\%20Is-

sue $\% 203 \% 20$ Septem-

ber\%2010/Vol_5_3_293_301_DP_Selvaraj.pdf.

12. Krolczyk, G.; Legutko, S.; Gajek, M. 2013. Predicting the surface roughness in the dry machining of duplex stainless steel (DSS), Metalurgija 52(2): 259-262.

https://hrcak.srce.hr/file/136497.

13. Selvaraj Philip, D.; Chandramohan, P.; Rajesh, P. K. 2015.Prediction of surface roughness in end milling operation of Duplex stainless steel using Response Surface Methodology, Journal of Engineering Science and Technology 10(3): $340-352$.

https:// docmh.com/the-philosophy-of money.html?utm_source=prediction-of-surface-roughness-in-end-milling-operation-of-duplex-stainless-steelusing-response-surface-methodology-pdf.

14. Waychal, S.; Kulkarni, A. V. 2015. Investigation of the effect of machining parameters on surface roughness and power consumption during the machining of AISI 304 Stainless Steel by DOE Approach, International Research Journal of Engineering and Technology (IRJET) 02(05): 484-490.

https:// www.irjet.net/archives/V2/i5/Irjet-V2I586. pdf.

15. Kumar, K. S.; Senthilkumaar, J. S.; Thirumalai, R. 2014. Chip morphology investigation among dry, wet and gas cooled machining of super duplex stainless steel, Applied Mechanics and Materials 592-594: 811-815. http://dx.doi.org/10.4028/ www.scientific.net/AMM. 592-594.811.

16. Sandvik Coromant .2017. Turning tools.

17. Mukherjee, I.; Ray, P. K. 2006. A review of optimization techniques in metal cutting processes, Computers et Industrial Engineering 50: 15-34.

http://dx.doi.org/10.1016/j.cie.2005.10.001.

18. Benardos, P. G.; Vosniakos, G. C. 2003. Predicting surface roughness in machining: a review. International Journal of Machine Tools \& Manufacture 43: 833-844. http://dx.doi.org/10.1016/S0890-6955(03)00059-2.

19. Ross, P. J. 1996. Taguchi Techniques for Quality Engineering Loss Function Orthogonal Experiments Parameter and Tolerance Design", second ed., McGraw-Hill, New York, NY.

20. Bouzid, L.; Yallese, M. A,; Chaoui, K.; Mabrouki. T,; Boulanouar, L. 2015. Mathematical modeling for turning on AISI 420 stainless steel using surface response methodology, Part B: Journal of Engineering Manufacture 229(1): 45-61.

http://dx.doi.org/10.1177/0954405414526385.

21. Berkani, S.; Yallese, M. A.; Boulanouar, L.; Mabrouki, T.2015. Statistical analysis of AISI304 austenitic stainless steel machining using $\mathrm{Ti}(\mathrm{C}, \mathrm{N}) / \mathrm{Al} 2 \mathrm{O} 3 / \mathrm{TiN}$ CVD coated carbide tool, International Journal of Industrial Engineering Computations 6: 1-14. http://dx.doi.org/10.5267/j.ijiec.2015.4.004.

22. Hessainia, Z.; Belbah, A,; Yallese, M. A,; Mabrouki, T.; Rigal, J. 2013. On the prediction of surface roughness in the hard turning based on cutting parameters and tool vibrations, Measurement 46: 1671-1681. http://dx.doi.org/10.1016/j.measurement. 2012.12.016.

23. Noordin, M. Y.; Venkatesh, V. C.; Chan, C. L; Abdullah, A .2001. Performance evaluation of cemented carbide tools in turning AISI 1010 steel, J. Mater. Process. Technol 116: 16-21.

http://dx.doi.org/10.1016/S0924-0136(01)00838-X.

24. Gökkaya, H. 2010.The effects of machining parameters on cutting forces, surface roughness, Built-Up Edge (BUE) and Built-Up Layer (BUL) during machining AA2014 (T4) alloy, Journal of Mechanical Engineering, 569: 584-593. 
http://www.sv-jme.eu/?ns_articles_pdf=/ns_articles/ files/ojs3/1530/submission/1530-1-2012-1-220171103.pdf\&id=5975.

25. Paro, J.; Hanninen, H.; Kauppinen, V. 2001. Tool wear and machinability of HIPed P/M and conventional cast duplex stainless steels, Wear 249: 279-284. http://dx.doi.org/ 10.1016/S0043-1648(01)00570-1.

26. Ezugwu, E. O.; Kim, S. K. 1995. The performance of cermet cutting tools when machining an Ni-Cr-Mo (En 24) steel, Lubrication Engineering 51 (2): 139-145. https://www.osti.gov/biblio/159575.

27. Kopač, J.; Bahor. M. 1999. Interaction of the technological history of a workpiece material and the machining parameters on the desired quality of the surface roughness of a product. J. Mater. Process. Technol. 9293: 381-7. http://dx.doi.org/10.1016/S0924-0136(99)00239-3.

28. Cassier, Z.; Prato, Y.; Muñoz-Escalona, P. 2004. Built-up edge effect on tool wears when turning steels at low cutting speed, Journal of Materials Engineering and Performance 13(5): 542-547. http://dx.doi.org/10.1361/10599490420629.

29. El-Tamimi, A. M.; El-Hossainy, T. M. 2010. Investigating the tool life, cutting force components, and surface roughness of AISI 302 stainless steel material under oblique machining, Materials and Manufacturing Processes 23(4): 427-438. http://dx.doi.org/10.1080/ 10426910801974846.

30. Swapnagandha S., Wagha; Atul P., Kulkarnib; Vikas G., Sargade. 2013. Machinability studies of austenitic stainless steel (AISI 304) using PVD cathodic arc evaporation (CAE) system deposited AlCrN/ TiAlN coated carbide inserts, Procedia Engineering 64: 907914. http://dx.doi.org/10.1016/j.proeng.2013.09. 167.

31. Kaczmarek, J. 1976. Principles of Machining by Cutting, Abrasion and Erosion, Peter Peregrinus Ltd, Stevenage.

32. Krolczyk, G. M.; Legutko. S. 2014. Experimental analysis by measurement of surface roughness variation in turning of duplex stainless steel, Metrology and Measurement Systems 21(4): 759-770.

http://dx.doi.org/ 10.2478/mms-2014-0060.

33. Chen,T.; Li, S.; Han, B.; Liu, G. 2014. Study on cutting force and surface micro-topography of hard turning of GCr15 steel, The International Journal of Advanced Manufacturing Technology 72: 1639-1645.

http:// dx.doi.org/10.1007/s00170-014-5778-7.

34. Fathallah, B. Ben; Saidi, R.; Dakhli, C.; Belhadi, S.; Yallese, M. A. 2019. Mathematical modelling and optimization of surface quality and productivity in turning process of AISI 12L14 free-cutting Steel, International Journal of Industrial Engineering Computations 10: 557-576. http://dx.doi.org/ 10.5267/j.ijiec.2019.3.001.

35. Saidi, R.; Fathallah, B. B.; Mabrouki, T.; Belhadi, S.; Yallese, M. A. 2019. Modeling and optimization of the turning parameters of cobalt alloy (Stellite 6) based on RSM and desirability function, The International Journal of Advanced Manufacturing Technology 100(9-12): 2945-2968. http:// doi.org/10.1007/ s00170-018-2816-x.

36. Derringer, G.; Suich, R. 1980. Simultaneous optimization of several response variables, Journal of Quality Technology 12: 214-219. http://dx.doi.org/ 10.1080/00224065.1980.11980968.

S. Boucherit, S. Berkani, M.A. Yallese, A. Haddad, S. Belhadi

\section{DRY TURNING OF X2CRNI18-09 USING COATED CARBIDE TOOLS: MODELLING AND OPTIMIZATION OF MULTIPLE PERFORMANCE CHARACTERISTICS}

S u m m a r y

The present paper investigates the cutting parameters pertaining to the turning of $\mathrm{X} 2 \mathrm{CrNi18}-09$ austenitic stainless steel that are studied and optimized using both RSM and desirability approaches. The cutting tool inserts used are the CVD coated carbide. The cutting speed, the feed rate and the depth of cut represent the main machining parameters considered. Their influence on the surface roughness and the cutting force are further investigated using the ANOVA method. The results obtained lead to conclude that the feed rate is the surface roughness highest influencing parameter with a contribution of $89.69 \%$. The depth of cut and the feed rate are further identified as the most important parameters affecting the cutting force with contributions of $46.46 \%$ and $39.04 \%$ respectively.

The quadratic mathematical models presenting the progression of the surface roughness and the cutting force and based on the machining parameters considered (cutting speed, feed rate and depth of cut) were obtained through the application of the RSM method. They are presented and compared to the experimental results. Good agreement is found between the two sections of the investigation.

Furthermore, the flank wear of the CVD-coated carbide tool (GC2015) is found to increase with both cutting speed and cutting time. A higher tool life represented by $t=44 \mathrm{~min}$ is observed at cutting speed, feed rate and depth of cut of $280 \mathrm{~m} / \mathrm{min}, 0.08 \mathrm{~mm} / \mathrm{rev}$ and $0.2 \mathrm{~mm}$ respectively. Moreover, and at low cutting speeds, the formation of micro weld is noticed and leads to an alteration of the surface roughness of the work piece.

Finally, optimizing the machining parameters with the objective of achieving an improved surface roughness was accomplished through the application of the Desirability Function approach. This enabled to finding out the optimal parameters for maximal material removal rate and best surface quality for a cutting speed of $350 \mathrm{~m} / \mathrm{min}$, a feed rate of $0.088 \mathrm{~mm} / \mathrm{rev}$ and a depth of cut of $0.9 \mathrm{~mm}$.

Keywords: machinability; austenitic stainless steel; CVD coated carbide tool; ANOVA; RSM; desirability approach.

Received December 28, 2018 Accepted November 21, 2019 